\title{
Dynamic Characteristics of Blade with Viscoelastic Damping Block Based on Complex Eigenvalue Method
}

\author{
Jiao Wang $\mathbb{D}^{1,2}$ Yue-hao Zhang, ${ }^{3}$ Tao Yu, ${ }^{1,2}$ and Qing-kai Han $\mathbb{D}^{4}$ \\ ${ }^{1}$ School of Mechatronics and Automobile Engineering, Yantai University, Yantai 264005, China \\ ${ }^{2}$ Key Laboratory of Advanced Manufacturing and Control Technology in Universities of Shandong, Yantai 264005, China \\ ${ }^{3}$ Engineering Training Center, Yantai University, Yantai 264005, China \\ ${ }^{4}$ Dalian Universities of Technology, Dalian 116024, China
}

Correspondence should be addressed to Jiao Wang; zoe_wjiao@163.com

Received 16 September 2017; Revised 2 February 2018; Accepted 25 February 2018; Published 5 April 2018

Academic Editor: Paulo B. Gonçalves

Copyright (c) 2018 Jiao Wang et al. This is an open access article distributed under the Creative Commons Attribution License, which permits unrestricted use, distribution, and reproduction in any medium, provided the original work is properly cited.

\begin{abstract}
A novel method for vibration suppression is proposed, adding a viscoelastic damping block to the root of the blade. The dynamical equation for a rotational viscoelastic damping block-blade (VE-blade) in a centrifugal force field and aerodynamic force field is established to calculate the dynamical natural frequency and responses of the VE-blade. Complex modulus model is applied to represent the constitutive law of viscoelastic material and shear force acting on the VE-blade formulates the effect of viscoelastic damping at the root interfaces. The dynamical equation of the system is established and the Galerkin method is used to discretize the partial differential equations to a 3-DOF system so as to compute the dynamic natural frequencies and responses of the VE-blade. Then the differential equations of motion with 3-DOF are numerically solved by using complex eigenvalue method. A cantilever VE-blade is simplified according to testing the first three natural frequencies of the real blade to obtain geometric parameters of cantilever beam. The effects of various parameters including thickness, storage modulus, loss factor of viscoelastic damping block, and rotating speed on natural frequency and modal damping ratio of VE-blade are discussed in detail.
\end{abstract}

\section{Introduction}

Blade is an important component of turbomachinery such as aeroengine, gas turbine, and high-end axial flow compressor. Under the condition of multifield coupling, the blade is subjected to relatively severe fluid and heat coupling excitation, and the resonance is inevitably generated due to its own dense natural frequency and complex vibration mode. In engineering practice, even to meet the requirements of the static strength and resistance to low cycle fatigue design, but due to the high stress level and the possible high frequency resonance, blade is still prone to high cycle fatigue failure. Therefore, the blade in the existing structure cannot be further optimized, and it is imperative to adopt an additional damping method to achieve vibration damping of the blade and improve its antivibration fatigue capability.

The vibration and noise can be inhibition in quite a wide frequency band with the high damping characteristics of viscoelastic materials $[1,2]$. The damping mechanism of viscoelastic damping material mainly depends on the internal friction polymer to dissipate vibration energy. The greater the internal friction of the polymer, the better the damping performance. But internal friction cannot be indefinitely increased, the main effect of polymer friction is the temperature and frequency, and each kind of viscoelastic damping material has its best working temperature and frequency range [3]. In recent years, the use of viscoelastic materials to improve the damping performance and the dynamic characteristics of components getting the people's attention, especially the thin-walled components, has been applied to aircraft engine, such as compressor blade, disc, and drum [47]. Now studies have shown that viscoelastic material with a high damping performance can effectively achieve damping vibration of structure and thus improve the component antivibration fatigue. With it stick on the blade dovetail structure as a damping layer (Figure 1), it will produce cyclical 


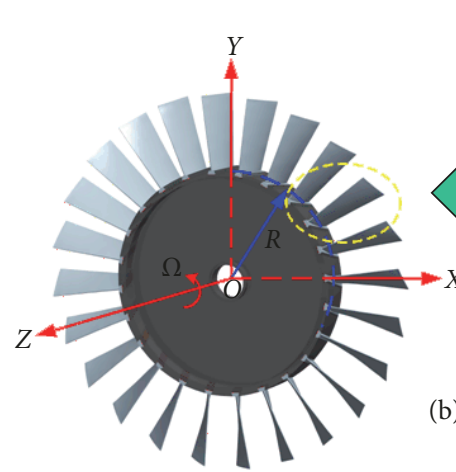

(b) Blade-disc

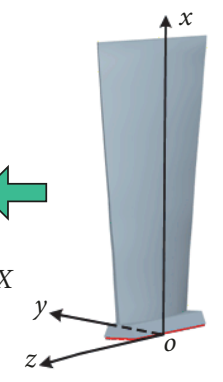

(b) Blade with viscoelastic damping block

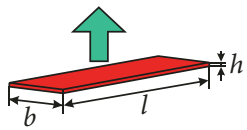

(c) Viscoelastic damping block

FIGURE 1: Schematic diagram of the blade-disc with viscoelastic damping block.

tensile deformation under the vibration of the component, so the phase difference between its stress and strain can dissipate energy dissipation and suppress the vibration of the blade, which has important engineering value.

The viscoelastic damping technology has been applied to turbine blades and other key components. Deng et al. [8] used cantilever with metal rubber block at its root to simulate the blade damping vibration. Li et al. [9] studied on new ways to suppress the resonance of fan's blade with the shoulder. The results show that the root rubber damper structure suppression effect on maximum vibration stress mode of blade tenons is obvious. Balmes et al. [4] found that the viscoelastic constrained layer improves the damping of aeroengine disks and changes its natural frequency and through experimental testing and numerical analysis verify that the damping performance of viscoelastic materials is affected by temperature. Miao [10] proposed that the natural frequency of the blade can be greatly reduced by applying nylon glue to the bottom of the blade root to meet the requirement of blade vibration. But the abnormal contact caused by irregular nylon glue and nonstandard assembly process easily leads to fretting wear and blade root fracture failure. Kocatürk [11] researched on the steady state responses of beam with elastic support under base excitation. Lagrange equation is adopted to establish the dynamic equation for the first two-order natural frequency and the results compared with the results obtained from Euler beam theory. This paper considers the effect of the viscoelastic damping and stiffness parameters on the steady state response, but not considering the effect of the friction on cantilever beam under elastic support, also does not consider the effect of rotational speed and the root of the cantilever fixed. Wang and Inman [12] studied the stiffness and damping of viscoelastic materials with frequency-dependent characteristics, which will affect the natural frequencies and responses of composite structures. Rafiee et al. [13] presented a critical review about dynamics, vibration, and control of rotating composite beams and blades. The active vibration control $[14,15]$ and passive control method [16] of the rotating beams and blades are introduced. Hosseini et al. [17] carried out the research on the nonlinear forced response analytic solution of piezoelectric composite viscoelastic beam under the action of nonlinear elastic support. Euler beam theory, Kelvin-Voigt viscoelastic materials model, and Hamilton principle are adopted to establish the dynamics equation, and considering the effect of nonlinear elastic stiffness, piezoelectric damping and elastic damping on structure nonlinear forced response. Min et al. [18] applied active piezoelectric vibration control method to decrease the vibration of the blade considering rotational effects. Through experiments and finite element simulation, it is verified that the piezoelectric material can effectively reduce the vibration of the blade.

Therefore, attaching viscoelastic materials at the bottom of blade root as a new vibration damping measure can effectively avoid the vibration fatigue of blade and improve the surface quality and effectively resist the impact, abrasion, and erosion caused by the external object. However, the related vibration theory of the nonlinear dynamic model and the mathematical model of the blade with viscoelastic materials is not perfect. The stiffness and damping are significantly increased after applying viscoelastic damping materials, and they are the main parameters of viscoelastic damping structure dynamic characteristics. For the dynamic analysis of composite structure, mainly using the modal strain energy method [19], the complex eigenvalue method and the direct frequency response method. Rao et al. [20] studied the beam with constrained damping layer and initial stress using residual deformation beam element and solved the loss factor with direct frequency response method and modal strain energy method. Rikards et al. [21] analyzed the vibration and damping of sandwich beam and plate using complex eigenvalue method and approximate energy method. Ravi et al. [22] used the modal superposition method to study the dynamic response of the beam to local or all of the free damping layer and the constrained damping layer. Chen and Shi [23] studied the local passive constrained damping beam using modal strain energy method, to extract the modal strain energy in each layer and solve the loss factor. Wang et al. [24] analyzed the frequency and dynamic response of the reinforced composite plate with viscoelastic damping layer using 
subspace iteration method and precise integration method. Analysis of the laminated plate and the laminated beam using damping matrix method, which combined Adams strain energy method with Raleigh damping model method, considered the dependence of the vibration frequency and temperature on the material properties and the dissipation coefficient of surface viscoelastic damping material established the frequency-dependent viscoelastic material damping matrix calculation method. Zhang and Chen [25] studied the damping characteristic of composite beam with viscoelastic material based on ANSYS using modal strain energy method and studied the influence of viscoelastic layer laying angle and position on the loss factor and natural frequency of the composite beam. Cortés and Elejabarrieta [26] used an iteration method to solve the eigenvalue and eigenvector of composite structure, obtained the eigenvalue and eigenvector of a static system without damping firstly, and then obtained the natural frequency and loss factor of composite plate structure using iteration method, the stiffness, and damping of composite plate structure change with frequency. Compare the result with obtained from modal strain energy method, which proved the accuracy of the iteration method.

In this paper, a general theory method for vibration suppression is proposed. The dynamical equation for a rotational cantilever VE-blade in a centrifugal force field and aerodynamic force field is established and the Galerkin method is used to discretize the partial differential equations to a 3-DOF system so as to compute the dynamic natural frequencies and responses of the VE-blade. Then the differential equations of motion with 3-DOF are numerically solved by using complex eigenvalue method. A cantilever VE-blade is simplified according to testing the first three natural frequencies of the real blade to obtain geometric parameters of cantilever beam. Compared with the experimental results, the rationality of the model is verified. The effects of viscoelastic damping material parameters such as thickness, storage modulus, loss factor, and rotational angular speed on the dynamic characteristics of VE-blade are further considered. The results show that increasing the thickness of the viscoelastic damping block, choosing the material with large storage modulus and loss factor can improve the modal damping ratio of the system and obtain better damping effect. With the increase of the rotational speed, the natural frequency of VE-blade increases gradually and the modal damping ratio decreases; indicating that with the increase of the rotational speed, the damping effect of the viscoelastic damping block decreases.

\section{Theoretical Analysis}

2.1. Simplified Mechanical Model of VE-Blade. Simplified VEblade can be regarded as a cantilever beam structure. The structure of blade-disc as shown in Figure 1 consists of blades, disc, and viscoelastic damping block, placed at the bottom of the blade. $O X Y Z$ is the global coordinate system, point $O$ is located in the center of the disc, and that rotates around the $z$-axis in angular velocity $\Omega$.

Take one blade from the blade-disc structure, set up local coordinate system $o x y z$, origin $o$ at the bottom of the viscoelastic block, and $R$ is the distance between $O$ and $o$. Make

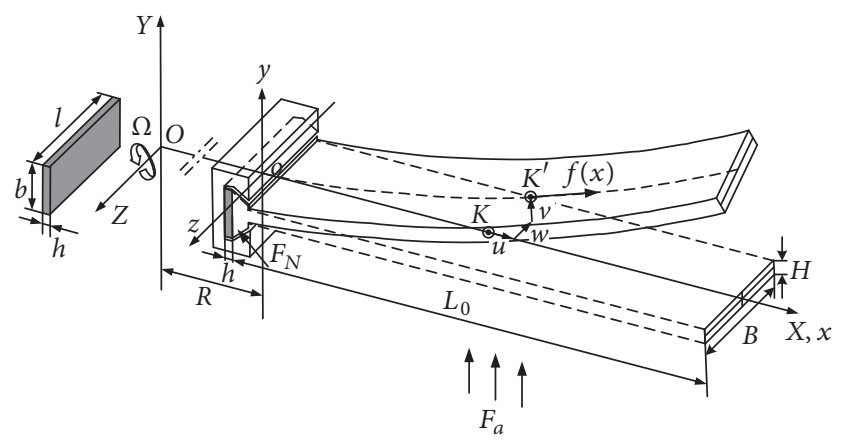

FIGURE 2: Schematic diagram of cantilever beam with viscoelastic damping block.

the first three-order natural frequency of the blade as the equivalent target; it can be simplified as a cantilever beam, as shown in Figure 2. The geometrical and material parameters of the blade are density $\rho$, elastic modulus $E$, Poisson's ratio $\mu$, length $L_{0}$, width $B$, thickness $H$, and cross-sectional area $A$. Geometrical and material parameters of viscoelastic damping block are length $l$, width $b$, thickness $h$, density $\rho_{1}$, energy storage modulus $E_{1}$, loss factor $\eta$, and Poisson's ratio $\mu_{1}$.

In general, viscoelastic materials have strong temperature and frequency dependence. The temperature is regarded as a constant in this paper. The complex Young's modulus of viscoelastic material is

$$
\begin{aligned}
E_{v}(\omega) & =E_{1}(\omega)+E_{2}(\omega) i=E_{1}(\omega)(1+i \eta(\omega)), \\
G_{v}(\omega) & =\frac{E_{v}(\omega)}{2\left(1+\mu_{1}\right)},
\end{aligned}
$$

where $E_{1}(\omega)$ is the real part of $E_{v}(\omega)$, called the storage modulus, $E_{2}(\omega)$ is the imaginary part of $E_{v}(\omega)$, called energy modulus, $\eta(\omega)=E_{2}(\omega) / E_{1}(\omega)$ is loss factor; $G_{v}(\omega)$ is complex shear modulus; $\mu_{1}$ is poison's ratio.

The viscoelastic damping block applied at the root of the blade is always in contact with the bottom of the blade and the bottom of the disc-slot. The movement of the blade produces tension, pressure, and shear force on the viscoelastic damping block [27]; it can free deformation in the length $(z$ axis) direction. Therefore, the stiffness and damping of the viscoelastic damping block are different in the thickness ( $x$ axis) direction and width ( $y$-axis) direction, where stiffness in $x$-axis direction is determined by the elasticity modulus, stiffness [28] in $y$-axis direction is determined by the shear modulus, respectively, as follows:

$$
\begin{aligned}
& k_{v x}=\frac{S k_{T}}{h} E_{v}(\omega), \\
& k_{v y}=\frac{S k_{s}}{h} G_{v}(\omega),
\end{aligned}
$$

where $k_{T}, k_{s}$ are shape factor of $k_{v x}, k_{v y}$, respectively.

In this paper, it is difficult to determine some parameters that affect $k_{T}$ and $k_{s}$ value, so $k_{T}=k_{s} \cong 1$.

Although there will be some error, it has little effect on the calculation results. Therefore, the acting point of force in the place where viscoelastic damping block and blade contact, the 
applied force on blade in tension and compression ( $x$-axis), and shear ( $y$-axis) direction produce by viscoelastic damping block can be written as the multiplication of equivalent stiffness and displacement component, as follows:

$$
\begin{aligned}
& F_{v x}=k_{v x} u_{v}=\frac{b l}{h} E_{1}(1+i \eta) u_{v}, \\
& F_{v y}=k_{v y} v_{v}=\frac{b l E_{1}}{2 h\left(1+\mu_{1}\right)}(1+i \eta) v_{v},
\end{aligned}
$$

where $u_{v}=u(h, t)$ and $v_{v}=v(h, t)$ are the displacement in $x$ and $y$ directions of the viscoelastic damping block acting point, respectively.

2.2. Dynamic Equations of VE-Blade. Newton mechanics method is adopted to establish the dynamic equations of VEblade. In order to establish an effective dynamic model of VEblade, the following assumptions are applied [29, 30]:

(1) VE-blade simplified as cantilever beam, its transverse vibration is microvibration.

(2) The material is isotropic, and the constitutive relation satisfies Hooke's law. The geometry parameters of cross section of blade and all cross section involved remain unchanged within the surface.

(3) VE-blade is simplified as cantilever beam; it perpendicular to the cross section of neutral axis before deformation and still planes after deformation. Shear and torsion and warping effect are ignored.

(4) Regardless the influence of surrounding medium damping and material internal damping of blade on vibration.

(5) Regardless of the Coriolis effect, ignore the longitudinal displacement $u$ along the axis of rotation direction displacement $w$ of the beam.

$K$ is a point on the central axis of cantilever beam microelement $\mathrm{d} x$, moving to the point $K^{\prime}$ after deformation, as shown in Figure 2. The position vector of microelement $\mathrm{d} x$ after deformation in inertial coordinate system $O X Y Z$ is expressed in $\mathbf{r}_{O}$.

$$
\mathbf{r}_{O}=(R+x) \mathbf{i}+v(x, t) \mathbf{j}
$$

where $\mathbf{i}, \mathbf{j}$, respectively, represent the unit vector in $O X, O Y$ axes.

The inertial velocity vector and acceleration vector of microelement $\mathrm{d} x$ can be expressed as

$$
\begin{aligned}
& \mathbf{v}_{a}=v_{x} \mathbf{i}+v_{y} \mathbf{j}, \\
& \mathbf{a}_{a}=a_{x} \mathbf{i}+a_{y} \mathbf{j},
\end{aligned}
$$

where

$$
\begin{aligned}
& v_{x}=-v(x, t) \Omega, \\
& v_{y}=(R+x) \Omega+\frac{\partial v(x, t)}{\partial t},
\end{aligned}
$$

$$
\begin{aligned}
& a_{x}=-\Omega^{2}(R+x)-2 \Omega \frac{\partial v(x, t)}{\partial t}, \\
& a_{y}=\frac{\partial v^{2}(x, t)}{\partial t^{2}}-\Omega^{2} v .
\end{aligned}
$$

Based on the principle of Newton, the dynamic equation of VE-blade is established. Take a microelement $\mathrm{d} x$ at coordinates $x$ in the simplified cantilever; it is force analysis as shown in Figure 3 [30]. The forces acting on the microelement have shear force $Q(x, t)$, centrifugal load $f(x)$, aerodynamic load $F_{a}(t)$, and bending moment $M(x, t)$. The deformations are $(\partial \mathrm{Q}(x, t) / \partial x) \mathrm{d} x, \mathrm{~d} f(x), \mathrm{d} F_{a}(t)$, and $\mathrm{d} M(x, t)$, respectively.

Equation is established according to the force balance and moment balance theory. Only consider the transverse vibration according to the assumption. Therefore, consider the force balance in $y$ direction, and then introduce the viscoelastic tangential force acting on blade root. The relational expression between transverse vibration displacement $v(x, t)$ and transverse forces is

$$
\begin{gathered}
Q(x, t)-\left[Q(x, t)+\frac{\partial Q(x, t)}{\partial x} \mathrm{~d} x\right]+F_{a}(t) \mathrm{d} x \\
-F_{v y} D(x-h) \mathrm{d} x=\rho A \mathrm{~d} x a_{y},
\end{gathered}
$$

where $Q(x, t)$ is the shear force on the cross section and $F_{a}(t)$ is the aerodynamic loading acted on pressure surface of blade. It generated by the first stage stator blade wake excitation expressed as

$$
F_{a}(t)=F_{a 0} \cos (j N \Omega t), \quad j=1,2,3, \ldots,
$$

where $F_{a 0}$ is amplitude of aerodynamic force, $j$ is the order of harmonic force, and $N$ is the number of blades in the upstream cascade row.

$D(x-h)$ is Dirac function and meets $D(x)=\{+\infty, x=$ $0 ; 0, x \neq 0\}$ and $\int_{-\infty}^{+\infty} D(x) \mathrm{d} x=1 . D(x-h)$ represents the viscoelastic force acting at the root of blade.

Substituting $a_{y}=\partial v^{2}(x, t) / \partial t^{2}-\Omega^{2} v$ into (7), divided by $\mathrm{d} x$, we have

$$
\begin{aligned}
\frac{\partial Q(x, t)}{\partial x}= & \rho A \Omega^{2} v-\rho A \frac{\partial v^{2}(x, t)}{\partial t^{2}}+F_{a}(t) \\
& -\frac{b l E_{1}}{2 h(1+\mu)}(1+i \eta) v_{v} D(x-h) .
\end{aligned}
$$

Point $K^{\prime}$ on neutral axis of microelement meets moment balance theory, and we have the rotation equation of microelement

$$
\begin{gathered}
\left(M(x, t)+\frac{\partial M(x, t)}{\partial x} \mathrm{~d} x\right)-M(x, t)-Q(x, t) \mathrm{d} x \\
-f(x) \frac{\partial v(x, t)}{\partial t} \mathrm{~d} x-F_{a}(t) \mathrm{d} x \frac{\mathrm{d} x}{2}=0,
\end{gathered}
$$




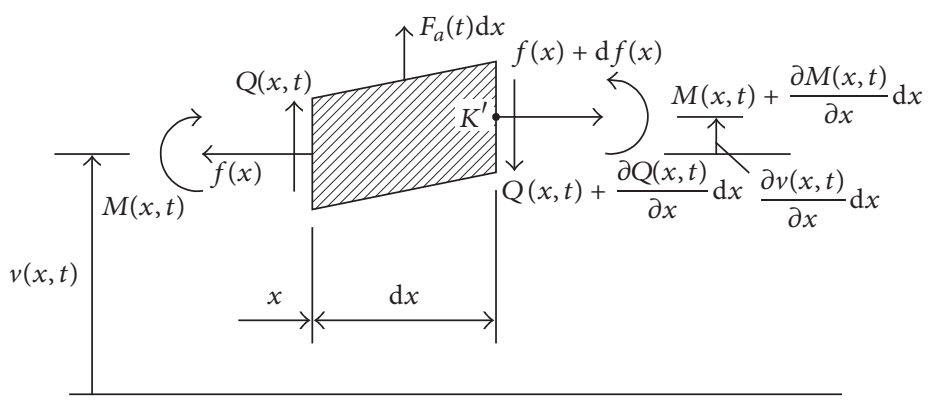

FIGURE 3: Mechanical schematics of blade microelement.

where $f(x)$ is the axial centrifugal load expressed as

$$
\begin{aligned}
f(x) & =\int_{x}^{L} \rho A \Omega^{2}(R+x) \mathrm{d} x \\
& =-\frac{1}{2} \rho A \Omega^{2}(x-L)(x+2 R+L) .
\end{aligned}
$$

Omit quadratic term contains $\mathrm{d} x$ and simplified equation (10) to

$$
Q(x, t)=\frac{\partial M(x, t)}{\partial x}-f(x) \frac{\partial v(x, t)}{\partial x} .
$$

According to assumption (1), under the condition of small deformation, the bending moment and deflection are the following relations:

$$
M(x, t)=E I \frac{\partial^{2} v(x, t)}{\partial x^{2}} .
$$

Substitute (12) and (13) into (9), based on the assumption of cantilever beam, we have the transverse vibration differential equation of system

$$
\begin{aligned}
& E I \frac{\partial^{4} v(x, t)}{\partial x^{4}}+\rho A \frac{\partial^{2} v(x, t)}{\partial t^{2}} \\
& \quad+\frac{1}{2} \rho A \Omega^{2}(x-L)(x+2 R+L) \frac{\partial^{2} v(x, t)}{\partial x^{2}} \\
& \quad-\rho A \Omega^{2}(x+R) \frac{\partial v(x, t)}{\partial x}-\rho A \Omega^{2} v(x, t) \\
& \quad+\left(\frac{b l E_{1}}{2 h(1+v)}(1+i \eta)\right) v_{v} D(x-h)=F_{a}(t) .
\end{aligned}
$$

\section{Solution Method to Dynamic Equation of VE-Blade}

3.1. Galerkin Discretization. The material parameters of the viscoelastic damping block can be regarded as a constant, and the dynamic equation of VE-blade can be discrete using Galerkin method and then can be solved in the frequency domain. In the given cantilever boundary condition, the solution of (14) is

$$
v(x, t)=\sum_{i=1}^{n} \phi_{i}(x) q_{i}(t),
$$

where $\phi_{i}(x)(i=1,2, \ldots, n)$ is the $i$ th order mode shape function and $q_{i}(t)$ is the corresponding generalized coordinates.

By the cantilever beam assumption, the eigenfunction as follows:

$$
\begin{aligned}
\phi_{i}(x)= & \cosh \frac{\lambda_{i}}{L} x-\cos \frac{\lambda_{i}}{L} x \\
& -\frac{\cosh \lambda_{i}+\cos \lambda_{i}}{\sinh \lambda_{i}+\sin \lambda_{i}}\left(\sinh \frac{\lambda_{i}}{L} x-\sin \frac{\lambda_{i}}{L} x\right),
\end{aligned}
$$

where $\lambda_{i}$ is eigenvalue and satisfies $\cos \left(\lambda_{i}\right) \cosh \left(\lambda_{i}\right)+1=0$; $L$ is the length of beam and satisfies $L=L_{0}+h$.

By the orthogonality of the vibration mode function, $\int_{0}^{L} \phi_{i}(x) \phi_{k}(x) \mathrm{d} x=\{0,(k \neq i) ; L,(k=i)\}, \int_{0}^{L} \phi_{i}^{(4)}(x) \phi_{k}(x) \mathrm{d} x$ $=\left\{0,(k \neq i) ; \lambda_{i}^{4} / L^{3},(k=i)\right\}$. Discretize the original system equation. Substitute (15) into (14), multiplied by $\phi_{k}(x)$ on both sides of the equation, integral on $x$ in the range $[0, L]$ gives

$$
\begin{aligned}
& E I \sum_{i=1}^{n} q_{i}(t) d_{1}+\rho A \sum_{i=1}^{n} \ddot{q}_{i}(t) d_{2}+\frac{1}{2} \rho A \Omega^{2} \sum_{i=1}^{n} q_{i}(t) d_{3} \\
& \quad-\rho A \Omega^{2} \sum_{i=1}^{n} q_{i}(t) d_{4}-\rho A \Omega^{2} \sum_{i=1}^{n} q_{i}(t) d_{2} \\
& \quad+\left(\frac{b l E_{1}}{2 h(1+\mu)}(1+i \eta)\right) \sum_{i=1}^{n} q_{i}(t) d_{5} \\
& =\int_{0}^{L} F_{a 0} \phi_{k}(x) \cos (j N \Omega t) \mathrm{d} x, \quad(k=1,2, \ldots, n),
\end{aligned}
$$

where $d_{1}=\int_{0}^{L} \phi_{i}^{(4)}(x) \phi_{k}(x) \mathrm{d} x, d_{2}=\int_{0}^{L} \phi_{i}(x) \phi_{k}(x) \mathrm{d} x, d_{3}=$ $\int_{0}^{L}(x-L)(x+2 R+L) \phi_{i}^{(2)}(x) \phi_{k}(x) \mathrm{d} x, d_{4}=\int_{0}^{L}(x+$ R) $\phi_{i}^{(1)}(x) \phi_{k}(x) \mathrm{d} x$, and $d_{5}=\int_{0}^{L} \phi_{i}(h) \phi_{k}(x) D(x-h) \mathrm{d} x$, where $\phi_{i}^{(m)}(x)=d^{m} \phi_{i}(x) / \mathrm{d} x$ represents $m$-order derivative of $x$ in vibration model function.

Equation (17) can be written as follows in the form of a matrix:

$$
\mathbf{M} \ddot{\mathbf{q}}(t)+\mathbf{K q}(t)=\mathbf{F}(t),
$$

where $\mathbf{q}(t)$ is the vector of generalized coordinates $q_{i}(t)(i=$ $1,2, \ldots, n), \mathbf{M}=\rho A \operatorname{Ldiag}(1,1, \ldots, 1)_{n \times n}$ is a mass matrix, 
$\mathbf{K}=\mathbf{K}_{e}+\mathbf{K}_{c}+\mathbf{K}_{v}(\omega)$ is the stiffness matrix of VE-blade and it has complex value and asymmetry, and $\mathbf{K}_{v}(\omega)$ has frequencydependent characteristics.
In the stiffness matrix $\mathbf{K}$, the elastic stiffness matrix $\mathbf{K}_{e}$, centrifugal stiffness matrix $\mathbf{K}_{c}$, viscoelastic stiffness matrix $\mathbf{K}_{v}(\omega)$, and its expression are as follows:

$$
\begin{aligned}
& \mathbf{K}_{e}=\frac{E I}{L^{3}} \operatorname{diag}\left(\lambda_{1}^{4}, \lambda_{2}^{4}, \ldots, \lambda_{n}^{4}\right)_{n \times n} \\
& \mathbf{K}_{c}=\frac{1}{2} \rho A \Omega^{2}\left[\begin{array}{ccc}
\int_{0}^{L}(x-L)(x+2 R+L) \phi_{1}^{(2)}(x) \phi_{1}(x) \mathrm{d} x & \cdots & \int_{0}^{L}(x-L)(x+2 R+L) \phi_{1}^{(2)}(x) \phi_{n}(x) \mathrm{d} x \\
\vdots & \ddots & \vdots \\
\int_{0}^{L}(x-L)(x+2 R+L) \phi_{n}^{(2)}(x) \phi_{1}(x) \mathrm{d} x & \cdots & \int_{0}^{L}(x-L)(x+2 R+L) \phi_{n}^{(2)}(x) \phi_{n}(x) \mathrm{d} x
\end{array}\right]_{n \times n} \\
& +\rho A \Omega^{2}\left[\begin{array}{ccc}
\int_{0}^{L}(x+R) \phi_{1}^{(1)}(x) \phi_{1}(x) \mathrm{d} x & \cdots & \int_{0}^{L}(x+R) \phi_{1}^{(1)}(x) \phi_{n}(x) \mathrm{d} x \\
\vdots & \ddots & \vdots \\
\int_{0}^{L}(x+R) \phi_{n}^{(1)}(x) \phi_{1}(x) \mathrm{d} x & \cdots & \int_{0}^{L}(x+R) \phi_{n}^{(1)}(x) \phi_{n}(x) \mathrm{d} x
\end{array}\right]_{n \times n} \\
& \text { - } \rho A \Omega^{2} \operatorname{Ldiag}(1,1, \ldots, 1)_{n \times n}, \\
& \mathbf{K}_{v}(\omega)=\left(\frac{b l E_{1}}{2 h(1+\mu)}(1+i \eta)\right) \operatorname{diag}\left(\phi_{1}^{2}(h), \phi_{2}^{2}(h), \ldots, \phi_{n}^{2}(h)\right)_{n \times n} .
\end{aligned}
$$

The excitation force vector $\mathbf{F}(t)$ is

$$
\begin{aligned}
\mathbf{F}(t) & =F_{a 0} \cos (j N \Omega t) \\
\cdot & {\left[\int_{0}^{L} \phi_{1}(x) \mathrm{d} x, \int_{0}^{L} \phi_{2}(x) \mathrm{d} x, \ldots, \int_{0}^{L} \phi_{n}(x) \mathrm{d} x\right]^{T} . }
\end{aligned}
$$

3.2. Solving the Natural Characteristics. The solution of the homogeneous equation $\mathbf{M} \ddot{\mathbf{q}}(t)+\mathbf{K q}(t)=\mathbf{0}$ has exponential

$$
\mathbf{q}(t)=\psi e^{i \lambda t}
$$

Substituting it into the homogeneous equation, we have a characteristic equation

$$
\left[\mathbf{K}-\lambda^{2} \mathbf{M}\right] \boldsymbol{\psi}=\mathbf{0}
$$

or

$$
\mathbf{K} \psi_{k}=\lambda_{k}^{2} \mathbf{M} \psi_{k}
$$

where $\lambda_{k}$ is the $k$ th eigenvalue and $\psi_{k}$ is the eigenvector of the corresponding eigenvalue $\lambda_{k}, k=1, \ldots, n$.

Considering that the matrix $\mathbf{M}$ is symmetric and $\mathbf{K}$ is asymmetric, the adjoint problem of the eigenequation needs to be solved. The left eigenvector can be obtained through the corresponding adjoint system

$$
\mathbf{K}^{T} \boldsymbol{\psi}_{j}=\lambda_{j}^{2} \mathbf{M}^{T} \boldsymbol{\psi}_{j},
$$

where $\lambda_{j}$ is the $j$ th eigenvalue and $\psi_{j}$ is the eigenvector of the corresponding eigenvalue $\lambda_{j}, j=1, \ldots, n$.
Premultiply (22b) by $\psi_{j}^{T}$ to get the following equation:

$$
\psi_{j}^{T} \mathbf{K} \psi_{k}=\lambda_{k}^{2} \psi_{j}^{T} \mathbf{M} \psi_{k}
$$

After (23) is transposed, then the right side is multiplied by $\psi_{k}$,

$$
\psi_{j}^{T} \mathbf{K} \psi_{k}=\lambda_{j}^{2} \psi_{j}^{T} \mathbf{M} \psi_{k}
$$

By $\operatorname{det}(\mathbf{M})=\operatorname{det}\left(\mathbf{M}^{T}\right)$ and $\operatorname{det}(\mathbf{K})=\operatorname{det}\left(\mathbf{K}^{T}\right),(22 \mathrm{a}),(22 \mathrm{~b})$, and (23) have the same characteristic value which is $\operatorname{det}(\mathbf{K}-$ $\left.\lambda_{k}^{2} \mathbf{M}\right)=\operatorname{det}\left(\mathbf{K}^{T}-\lambda_{j}^{2} \mathbf{M}^{T}\right)$; by (24) minus (25) we have

$$
\left(\lambda_{k}^{2}-\lambda_{j}^{2}\right) \psi_{j}^{T} \mathbf{M} \psi_{k}=0 .
$$

If all the eigenvalues are different, when $k \neq j, \lambda_{k}^{2} \neq \lambda_{j}^{2}$. We have

$$
\begin{aligned}
\psi_{j}^{T} \mathbf{M} \psi_{k} & =0 \\
\psi_{j}^{T} \mathbf{K} \psi_{k} & =0
\end{aligned}
$$

when $k=j$, we have

$$
\begin{gathered}
\psi_{j}^{T} \mathbf{M} \psi_{j}=m_{j}, \\
\psi_{j}^{T} \mathbf{K} \psi_{j}=k_{j},
\end{gathered}
$$

where $m_{j}$ is the modal mass, $k_{j}$ is the modal stiffness, and $j=1, \ldots, n$. 
The relationship between eigenvalues and modal mass and modal stiffness is

$$
\lambda_{j}^{2}=\frac{k_{j}}{m_{j}} .
$$

Eigenvectors $\psi_{j}$ and $\psi_{k}$ have weighted orthogonality about $\mathbf{M}$ and $\mathbf{K}$,

$$
\begin{gathered}
\boldsymbol{\psi}_{j}^{T} \mathbf{M} \psi_{k}= \begin{cases}0, & j \neq k, \\
m_{j}, & j=k,\end{cases} \\
\boldsymbol{\psi}_{j}^{T} \mathbf{K} \psi_{k}= \begin{cases}0, & j \neq k, \\
k_{j}, & j=k .\end{cases}
\end{gathered}
$$

The $j$ order eigenvalues of complex stiffness system can be written as [31]

$$
\lambda_{j}^{2}=\omega_{j}^{2}\left(1+i \eta_{j}\right)
$$

where $\omega_{j}$ is the natural frequency and $\eta_{j}$ is the modal loss factor of the system.

The natural frequency is

$$
\omega_{j}=\sqrt{\operatorname{Re}\left(\lambda_{j}^{2}\right)}
$$

The loss factor is

$$
\eta_{j}=\frac{\operatorname{Im}\left(\lambda_{j}^{2}\right)}{\operatorname{Re}\left(\lambda_{j}^{2}\right)}
$$

3.3. Solution of the Frequency Response. The frequency response of VE-blade can be obtained by transforming (17) in the frequency domain. Equation (18) can be expressed as the equation of motion in the frequency domain through Fourier transform [5].

$$
\left[-\lambda^{2} \mathbf{M}+\mathbf{K}(\lambda)\right] \mathbf{Q}(\lambda)=\mathbf{F}(\lambda),
$$

where $\mathbf{F}(\lambda)$ and $\mathbf{Q}(\lambda)$ are the Fourier transform result of $\mathbf{F}(t)$ and $\mathbf{q}(t)$.

The VE-blade is subjected to excitation as follows:

$$
\begin{aligned}
& \mathbf{F}(\lambda)=\mathbf{H}_{F}(\lambda) e^{i \Phi(\lambda)}=F_{a 0}\left[\int_{0}^{L} \phi_{1}(x) \mathrm{d} x,\right. \\
& \left.\quad \int_{0}^{L} \phi_{2}(x) \mathrm{d} x, \ldots, \int_{0}^{L} \phi_{n}(x) \mathrm{d} x\right]^{T} D(\lambda-j N \Omega),
\end{aligned}
$$

where $\mathbf{H}_{F}(\lambda)$ are the amplitude of $\mathbf{F}(\lambda)$ and $D(\lambda-j N \Omega)$ is Dirac function and meets $D(x)=\{+\infty, x=0 ; 0, x \neq 0\}$ and $\int_{-\infty}^{+\infty} D(x) \mathrm{d} x=1$. is

Displacement response in frequency domain of VE-blade

$$
Q(\lambda)=\mathbf{H}_{q}(\lambda) e^{i \Phi(\lambda)},
$$

where $\mathbf{H}_{q}(\lambda)$ are the amplitude of $Q(\lambda)$.
Substituting (35) and (36) into (34), we have

$$
\mathbf{H}_{q}(\lambda)=\mathbf{H}(\lambda) \mathbf{H}_{F}(\lambda) .
$$

That is,

$$
\mathbf{H}(\lambda)=\left[-\lambda^{2} \mathbf{M}+\mathbf{K}(\lambda)\right]^{-1},
$$

where $\mathbf{H}(\lambda)$ is frequency response function matrix.

If $\psi$ is taken as a transformation matrix, we have

$$
\mathbf{q}(t)=\psi \mathbf{y}(t),
$$

where $\mathbf{y}(t)$ is modal coordinates vector.

Equation (39) can be expressed as the equation of motion in the frequency domain through Fourier transform, we have

$$
\mathbf{Q}(\lambda)=\psi(\lambda) \mathbf{Y}(\lambda) .
$$

Substitute (39) into (18), and then multiply the left side by $\psi^{T}$. According to the orthogonality of the modal vectors, the equation of forced vibration under modal coordinates is obtained.

$$
\operatorname{diag}\left[m_{j}\right] \ddot{\mathbf{y}}(t)+\operatorname{diag}\left[k_{j}\right] \mathbf{y}(t)=\psi^{T} \mathbf{F}(t),
$$

where diag is diagonal matrix.

Equation (41) can be expressed as the equation of motion in the frequency domain through Fourier transform; we have

$$
\operatorname{diag}\left[-\lambda^{2} m_{j}+k_{j}\right] \mathbf{Y}(\lambda)=\psi^{T}(\lambda) \mathbf{F}(\lambda) .
$$
is

Displacement response in frequency domain of VE-blade

$$
\mathbf{Y}(\lambda)=\mathbf{H}_{Y}(\lambda) e^{i \Phi(\lambda)} .
$$

Substituting (43) into (42), we have

$$
\operatorname{diag}\left[-\lambda^{2} m_{j}+k_{j}\right] \mathbf{H}_{Y}(\lambda)=\psi^{T}(\lambda) \mathbf{H}_{F}(\lambda) .
$$

That is,

$$
\mathbf{H}_{Y}(\lambda)=\operatorname{diag}\left[-\lambda^{2} m_{j}+k_{j}\right]^{-1} \psi^{T}(\lambda) \mathbf{H}_{F}(\lambda) .
$$

Substituting (36) and (43) into (40), the amplitude of frequency response $\mathbf{H}_{q}(\lambda)$ is

$$
\mathbf{H}_{q}(\lambda)=\psi(\lambda) \operatorname{diag}\left[-\lambda^{2} m_{j}+k_{j}\right]^{-1} \psi^{T}(\lambda) \mathbf{H}_{F}(\lambda) .
$$

The frequency domain response amplitude of the oxyz coordinate system is the superposition of the frequency response amplitude in the generalized coordinates, so we have

$$
H\left(x_{0}\right)=\phi\left(x_{0}\right) \mathbf{H}_{q}(\lambda)=\sum_{i=1}^{n} \phi_{i}\left(x_{0}\right) H_{q i}(\lambda),
$$

where $x_{0}$ is the height between the place picking up response and the origin $o$ and $h \leq x_{0} \leq L$, at the blade root $x_{0}=h$, at the top of blade $x_{0}=L$. According to (14), $\phi\left(x_{0}\right)=\left[\phi_{1}\left(x_{0}\right)\right.$, $\left.\phi_{2}\left(x_{0}\right), \ldots, \phi_{n}\left(x_{0}\right)\right]^{T}$ is the vector of modal shape function at $x_{0}$. 
TABLE 1: Material parameters of the viscoelastic damping block.

\begin{tabular}{lcccc}
\hline Material & Elasticity modulus $/ \mathrm{Pa}$ & Poisson's ratio & Density $/\left(\mathrm{kg} / \mathrm{m}^{3}\right)$ & Loss factor \\
\hline $\mathrm{Zn}-33$ & $1 \times 10^{9}$ & 0.498 & 930 & 0.9683 \\
\hline
\end{tabular}
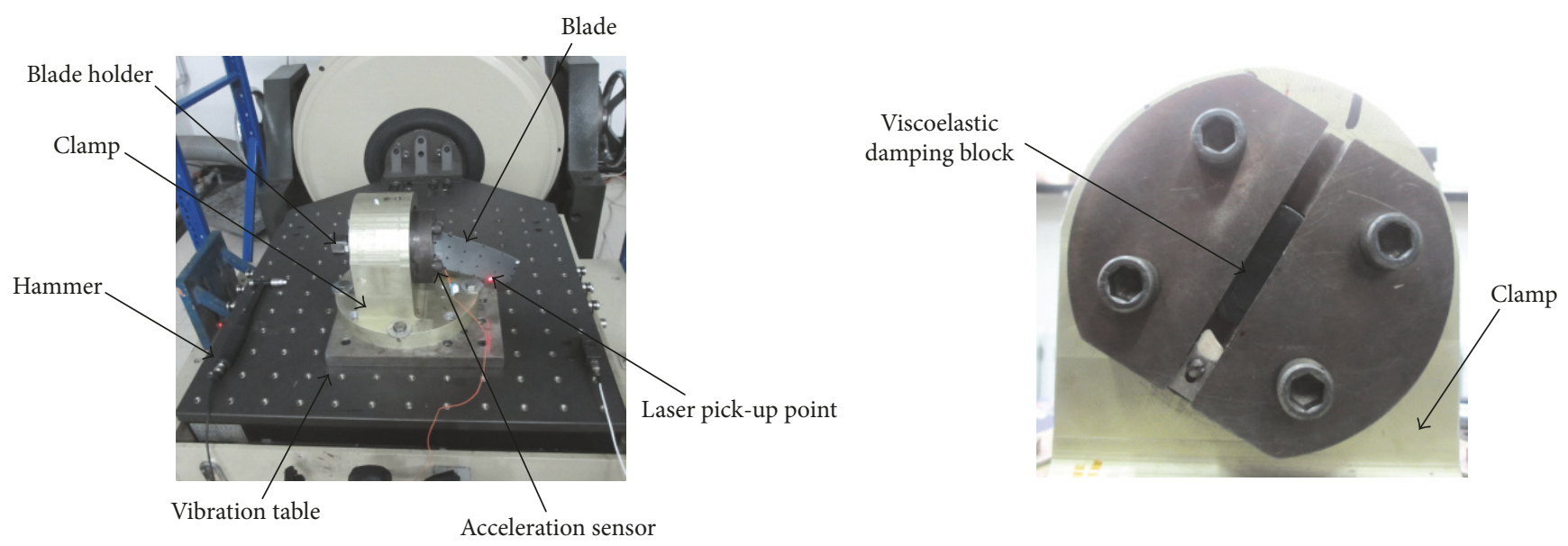

Figure 4: Test device of VE-blade.

TABLE 2: Geometric parameters of viscoelastic material Zn-33/mm.

\begin{tabular}{lcc}
\hline Length $l$ & Width $b$ & Thickness $h$ \\
\hline 45.60 & 11.30 & 1.48 \\
\hline
\end{tabular}

\section{Numerical Results and Discussion}

The effect of viscoelastic damping block on natural frequency and modal damping ratio of the blade is studied. The parameters of viscoelastic damping block mainly include thickness, energy storage modulus, and loss factor. Meanwhile, consider the influence of rotational angular velocity on the natural characteristics of VE- blade.

The number of preset blade stators $N=36$, the resonant frequency $j=1$, the radius of the disc are a multiple of the length of the blade, $R=1.2 L$.

In order to compare with the static state experimental data, the rotational speed is 0 ; when considering the effect of rotational angular velocity on the natural frequency and modal damping ratio of the VE-blade, the speed range is 0 60000 rpm.

When the blade is simplified, only the first three-order modes $(n=3)$ are truncated. In (18), the dimension of the $M$ and $K$ matrices is 3 .

4.1. Material and Geometric Parameters of VE-Blade. In the analysis, elastic modulus of viscoelastic damping block is constant. Material parameters and the geometry size of viscoelastic damping block are shown in Tables 1 and 2 .

The material and geometric parameters of the blade are confirmed by the measured method and the material parameters of the blade are shown in Table 3.

The $30 \mathrm{~N} \cdot \mathrm{m}$ torque is applied to the blade holder; fix the rubber block made by ZN-33 on the blade clamp slot and blade root. Vibration table is used to sweep the blade and
VE-blade to get the natural frequencies, then the blade is excited by constant frequency to get the resonance response. Envelope method is used to obtain the modal damping ratio of a certain vibration frequency, using a laser vibrometer pickup blade response data. The test device is shown in Figure 4.

Theoretical analysis in this chapter mainly considers material damping effect on the natural frequency and response of the blade after adding viscoelastic damping block. Obtain the blade damping ratio by Rayleigh method using the experimental data before adding viscoelastic damping block. Material damping is used to represent the blade damping after adding viscoelastic damping block. The experimental data is shown in Table 4.

A cantilever VE-blade is simplified according to the testing the first three natural frequency of the real blade to obtain geometric parameters of cantilever beam. Calculating formula of natural frequency of cantilever beam is used.

$$
\omega_{i}=\frac{\lambda_{i}^{2}}{L_{o}^{2}} \sqrt{\frac{E I}{\rho A}}=\frac{\lambda_{i}^{2} H}{L_{o}^{2}} \sqrt{\frac{E}{12 \rho}}
$$

where $\omega_{i}$ is natural frequency of testing blade.

The length of the viscoelastic damping layer is used as the width of the cantilever beam; that is, $B=l=45.6 \mathrm{~mm}$. Then the length of cantilever beam is measured blade height; that is, $130 \mathrm{~mm}$, and then the thickness $H$ of the cantilever beam is obtained. The geometrical parameters of the first three-order cantilever beam are shown in Table 5 .

4.2. Resonance Characteristics. The natural properties of the VE-blade are calculated and compared with the test data. Using aerodynamic load simulates excitation energy and changes the excitation energy from $0.5 \mathrm{~g}$ to $3 \mathrm{~g}$, to calculate the resonance characteristics of the blade with one-layer 
TABLE 3: Material parameters of the blade.

\begin{tabular}{|c|c|c|c|c|}
\hline Material & Elasticity modulus/Pa & Poisson's ratio & Density $/\left(\mathrm{kg} / \mathrm{m}^{3}\right)$ & Loss factor \\
\hline 1Cr11Ni2W2MoV & $214 \times 10^{9}$ & 0.3 & 7800 & - \\
\hline
\end{tabular}

TABLE 4: Natural frequencies and modal damping ratio of the blade.

\begin{tabular}{lccc}
\hline Order & Mode shape & Natural frequency/Hz & Damping ratio/\% \\
\hline$(1)$ & First bending & 253.25 & 0.0954 \\
$(2)$ & First bending & 1011.75 & 0.0818 \\
$(3)$ & First torsion & 1189.50 & 0.0242 \\
\hline
\end{tabular}

TABLE 5: Geometric parameters of the blade are simplified as cantilever beam $/ \mathrm{mm}$.

\begin{tabular}{lccc}
\hline Order & Length $L_{o}$ & Width $B$ & Thickness $H$ \\
\hline$(1)$ & 130 & 45.6 & 5.07 \\
$(2)$ & 130 & 45.6 & 3.22 \\
$(3)$ & 130 & 45.6 & 1.35 \\
\hline
\end{tabular}

viscoelastic damping block. Remove the viscoelastic force term in (14), so that the thickness of viscoelastic damping block $h=0$; we can get the resonance curve of the pure blade.

The frequency domain response of the VE-blade and the blade tip in stationary state are shown in Figure 5.

In this study, all excitation forces are assumed to be uniform with $0.5 \mathrm{~g}$.

As can be seen from Figure 5, the added viscoelastic block shifts the first three-order resonance frequency of the blade from $253 \mathrm{~Hz}$ to $247.34 \mathrm{~Hz}, 1012.15 \mathrm{~Hz}$ to $989.57 \mathrm{~Hz}$, and $1189.25 \mathrm{~Hz}$ to $1163.8 \mathrm{~Hz}$, respectively. The natural frequency decreases by $2.25 \%, 2.23 \%$, and $2.14 \%$, respectively. The first three-order vibration amplitude at the tip of the VE-blade compared with the pure blade decreases from $0.3382 \mathrm{~mm}$ to $0.2256 \mathrm{~mm}, 0.0106 \mathrm{~mm}$ to $0.0103 \mathrm{~mm}$, and $0.0053 \mathrm{~mm}$ to $0.0017 \mathrm{~mm}$, respectively. The vibration amplitude decreased by $33.29 \%, 2.83 \%$, and $67.92 \%$, and the damping effect is obvious. The experimental test data are shown in Table 6 , in which the first three-order amplitude decreased by $13.36 \%$, $21.9 \%$, and $11.8 \%$. The experimental value and the simulation value trend were basically consistent, which verified the rationality of the numerical simulation.

4.3. Response Characteristics. For the pure blade with viscoelastic damping block, its thickness is one layer, two layers, three layers, respectively. Experimental results and simulation result of the first three-order resonant amplitude at the tip of VE-blade for the above three cases are shown in Figure 6. In this study, all excitation forces are assumed to be uniform with $0.5 \mathrm{~g}$ to consider the effect of different layers of viscoelastic damping block on the response characteristic of the blade.

As can be seen from Figure 6, for the pure blade with viscoelastic damping block, its thickness is one layer, two layers, and three layers, respectively. The simulated and experimental values of the first three-order resonant amplitude at the tip of the blade for the above three cases are shown in Figure 6 .
In Figure 6(a), the deviation of simulation results and experiment results with above three cases are $28.5 \%, 17.6 \%$, and $63.9 \%$, respectively. With the resonance response of blade with one and two layers' viscoelastic damping block lower than the pure blade, we can see from the experiment result that the resonance response fell by $13.36 \%$, and $16.87 \%$ compared with the pure blade. But the three layers of viscoelastic damping block is applied to the blade, the resonance response decreases by $3.1 \%$ in simulation result and increased in experiment result.

As can be seen from Figure 6(b), the deviation of simulation result and experiment result with above three cases are $53.25 \%, 52.9 \%$, and $26.8 \%$. The resonance response of blade with two layers viscoelastic damping block is increased by $2.3 \%$ than the pure blade in experiment result and lower in simulation result. While the resonance response of blade with one and three layers viscoelastic damping block decreased by $36.9 \%, 39.6 \%$ in simulation result and decreased by $21.9 \%$, $38.5 \%$ in experiment result. The damping effect is obvious.

As can be seen from Figure 6(c), the deviation of simulation result and experiment result with above three cases are $96.9 \%, 95.5 \%$, and $97.9 \%$. The resonance response of blade with above three cases decreased by $83.1 \%, 72.3 \%$, and $86.9 \%$ compared with the pure blade in simulation result, the damping effect is obvious. In experiment result, the resonance response of blade with one and two layers viscoelastic damping block decreased by $11.8 \%$ and $4.3 \%$, increased by $2.0 \%$ after applied three layers viscoelastic damping block.

Therefore, the results show that the calculated results are smaller than the experimental results, but they have the same trend. Possible reasons are using gas excitation to simulate the base excitation so that the actual exciting force is insufficient. Blade model is simplified according to the natural frequency, without considering the change of loss factor, thus leading to vibration amplitude error exists.

4.4. Effect of Viscoelastic Damping Parameters on Natural Characteristics. Consider the effect of the viscoelastic damping block's thickness, storage modulus, loss factor, and rotational angular velocity on the natural frequency and modal damping ratio of the VE-blade.

4.4.1. Effect of Viscoelastic Damping Block's Thickness. Change the viscoelastic damping block's thickness from $1 \mathrm{~mm}$ to $6 \mathrm{~mm}$, the natural frequency, and modal damping ratio of the VE-blades shown in Table 7 . Figure 7 shows the influence of the thickness change on the natural frequency and modal damping ratio of viscoelastic damping block-blade.

As can be seen from Table 7 and Figure 7, with the increase of the thickness of the viscoelastic damping block, the natural frequency of the VE-blade is slowly decreasing, and the modal damping ratio is gradually increasing. The thickness of viscoelastic damping block is $1 \mathrm{~mm}$ and $2 \mathrm{~mm}$ as 

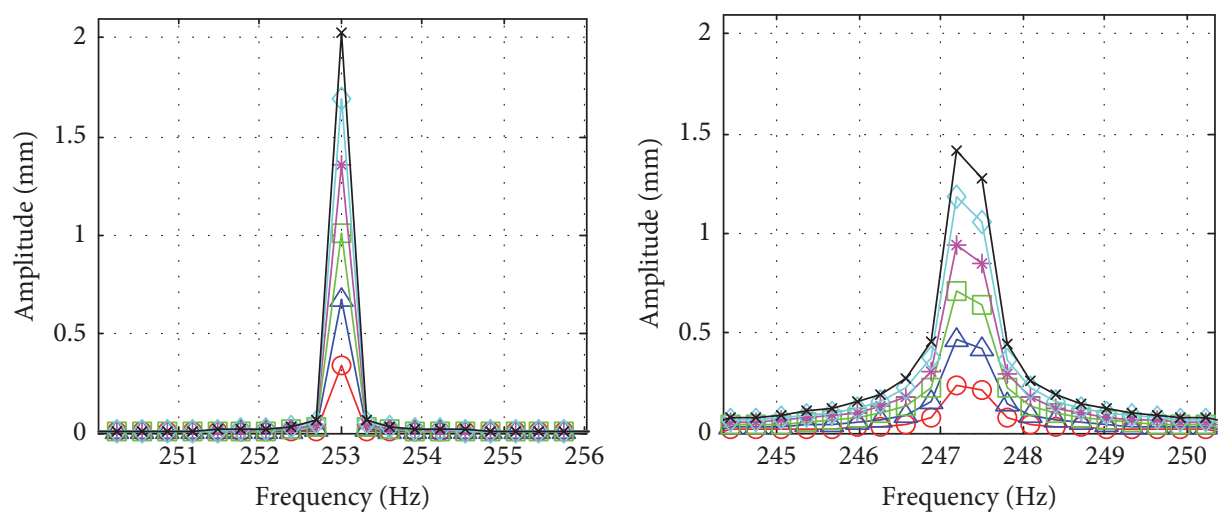

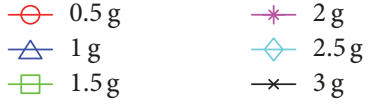

(a) The first-order amplitude of pure blade

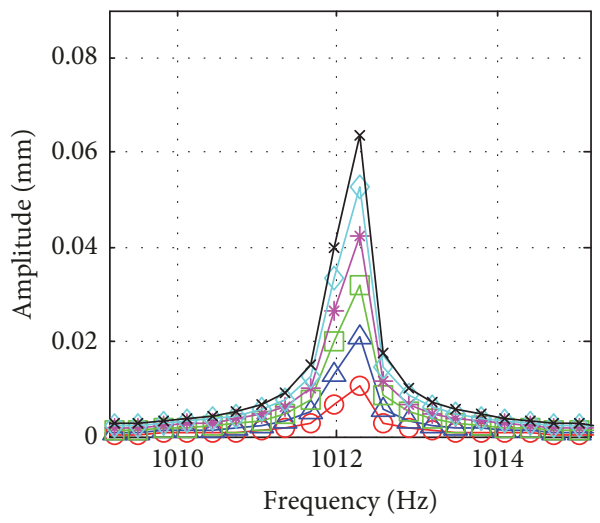

$$
\begin{array}{ll}
\ominus 0.5 \mathrm{~g} & * 2 \mathrm{~g} \\
\triangle 1 \mathrm{~g} & \smile 2.5 \mathrm{~g} \\
\square 1.5 \mathrm{~g} & *-3 \mathrm{~g}
\end{array}
$$

(c) The second-order amplitude of pure blade

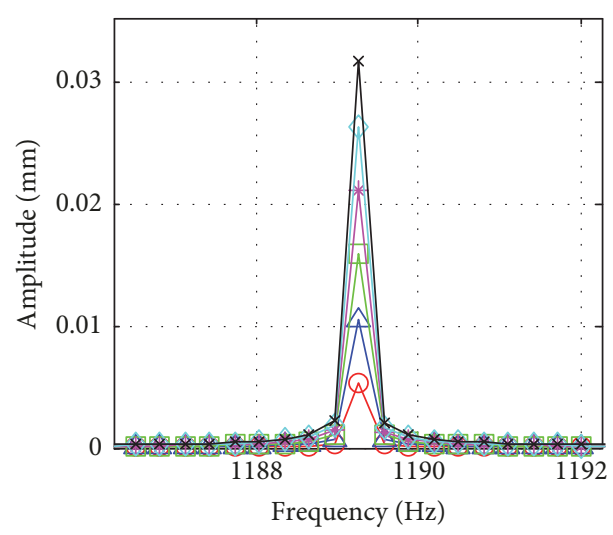

$$
\begin{array}{ll}
\ominus 0.5 \mathrm{~g} & * 2 \mathrm{~g} \\
\triangle 1 \mathrm{~g} & \smile 2.5 \mathrm{~g} \\
\square 1.5 \mathrm{~g} & *-3 \mathrm{~g}
\end{array}
$$

(e) The third-order amplitude of pure blade

$$
\begin{array}{ll}
\ominus 0.5 \mathrm{~g} & * 2 \mathrm{~g} \\
\triangle 1 \mathrm{~g} & -2.5 \mathrm{~g} \\
\square 1.5 \mathrm{~g} & *-3 \mathrm{~g}
\end{array}
$$

(b) The first-order amplitude of VE-blade

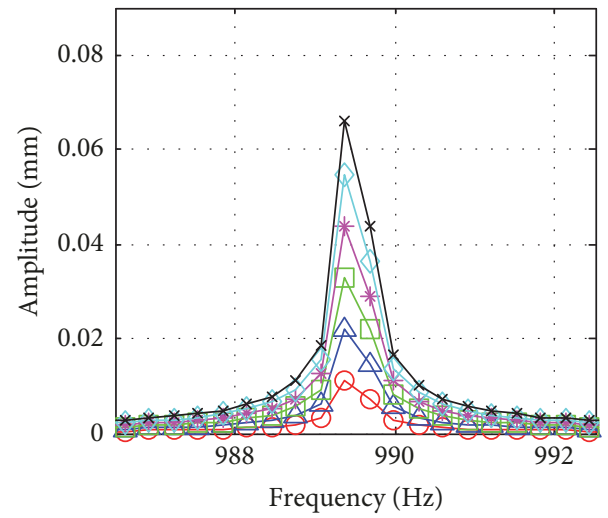

$$
\begin{array}{ll}
-0.5 \mathrm{~g} & \rightarrow 2 \mathrm{~g} \\
\triangle 1 \mathrm{~g} & \succ 2.5 \mathrm{~g} \\
\square 1.5 \mathrm{~g} & \rightarrow-3 \mathrm{~g}
\end{array}
$$

(d) The second-order amplitude of VE-blade

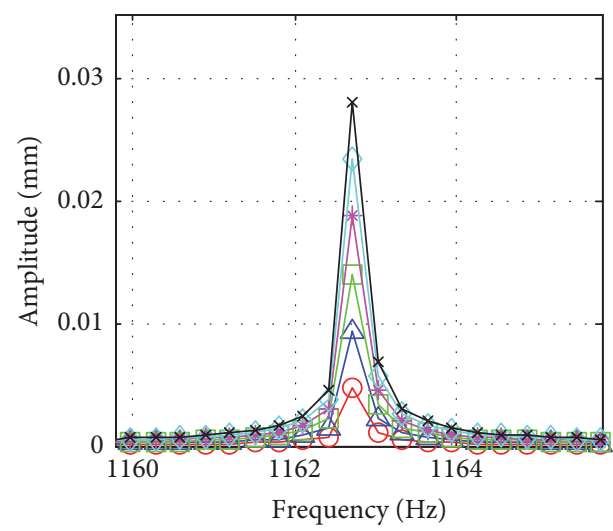

$$
\begin{array}{ll}
\bigcirc 0.5 \mathrm{~g} & * 2 \mathrm{~g} \\
\triangle 1 \mathrm{~g} & -2.5 \mathrm{~g} \\
\square 1.5 \mathrm{~g} & \rightarrow-3 \mathrm{~g}
\end{array}
$$

(f) The third-order amplitude of VE-blade

FIGURE 5: Comparison of numerical results of resonance characteristics of the VE-blade and pure blade. 
TABLE 6: Resonant amplitude obtained by test $/ \mathrm{mm}$.

\begin{tabular}{lcccc}
\hline Order & Excitation energy & Response point & Pure blade/mm & VE-blade/mm \\
\hline$(1)$ & $0.5 \mathrm{~g}$ & Blade tip & 0.3645 & 0.3158 \\
$(2)$ & $1 \mathrm{~g}$ & Blade tip & 0.0283 & 0.0221 \\
$(3)$ & $1 \mathrm{~g}$ & Blade tip & 0.0669 & 0.0590 \\
\hline
\end{tabular}

TABLE 7: Natural frequencies and modal damping ratios of the blade with different thickness of viscoelastic damping block.

\begin{tabular}{|c|c|c|c|c|c|c|}
\hline \multirow[b]{2}{*}{ Thickness/mm } & \multicolumn{2}{|c|}{ First order } & \multicolumn{2}{|c|}{ Second order } & \multicolumn{2}{|c|}{ Third order } \\
\hline & $\begin{array}{c}\text { Natural } \\
\text { frequency/Hz }\end{array}$ & $\begin{array}{c}\text { Modal damping } \\
\text { ratio/\% }\end{array}$ & $\begin{array}{c}\text { Natural } \\
\text { frequency/Hz }\end{array}$ & $\begin{array}{c}\text { Modal damping } \\
\text { ratio/\% }\end{array}$ & $\begin{array}{c}\text { Natural } \\
\text { frequency/Hz }\end{array}$ & $\begin{array}{c}\text { Modal damping } \\
\text { ratio/\% }\end{array}$ \\
\hline 1 & 249.15 & $6.05 e-04$ & 996.78 & $2.28 e-03$ & 1171.5 & $3.04 e-02$ \\
\hline 2 & 245.39 & $4.77 e-03$ & 981.89 & $1.77 e-02$ & 1156.2 & $2.31 e-01$ \\
\hline 3 & 241.75 & $1.59 e-02$ & 967.58 & $5.78 e-02$ & 1144.9 & $7.35 e-01$ \\
\hline 4 & 238.21 & $3.70 e-02$ & 952.80 & $1.33 e-01$ & 1138.6 & 1.63 \\
\hline 5 & 234.78 & $7.12 e-02$ & 941.00 & $2.50 e-01$ & 1137.9 & 2.94 \\
\hline 6 & 231.46 & $1.21 e-01$ & 928.82 & $4.17 e-01$ & 1143.1 & 4.66 \\
\hline
\end{tabular}

TABLE 8: Natural frequencies and modal damping ratios of the blade with different storage modulus.

\begin{tabular}{|c|c|c|c|c|c|c|}
\hline \multirow{2}{*}{$\begin{array}{l}\text { Storage } \\
\text { modulus/Mpa }\end{array}$} & \multicolumn{2}{|c|}{ First order } & \multicolumn{2}{|c|}{ Second order } & \multicolumn{2}{|c|}{ Third order } \\
\hline & $\begin{array}{c}\text { Natural } \\
\text { frequency/Hz }\end{array}$ & $\begin{array}{l}\text { Modal damping } \\
\text { ratio/\% }\end{array}$ & $\begin{array}{c}\text { Natural } \\
\text { frequency/Hz }\end{array}$ & $\begin{array}{c}\text { Modal damping } \\
\text { ratio/\% }\end{array}$ & $\begin{array}{c}\text { Natural } \\
\text { frequency/Hz }\end{array}$ & $\begin{array}{l}\text { Modal damping } \\
\text { ratio/\% }\end{array}$ \\
\hline 500 & 247.34 & $9.73 e-10$ & 989.49 & $3.65 e-09$ & 1162.6 & $4.82 e-08$ \\
\hline 700 & 241.86 & $1.35 e-09$ & 967.59 & $5.05 e-09$ & 1136.9 & $6.68 e-08$ \\
\hline 1000 & 236.56 & $1.90 e-09$ & 946.40 & $7.14 e-09$ & 1112.0 & $9.44 e-08$ \\
\hline 2000 & 231.44 & $3.77 e-09$ & 925.90 & $1.41 e-08$ & 1087.9 & $1.87 e-07$ \\
\hline 3000 & 226.48 & $5.59 e-09$ & 906.06 & $2.09 e-08$ & 1064.6 & $2.77 e-07$ \\
\hline 4000 & 221.68 & $7.38 e-09$ & 886.85 & $2.77 e-08$ & 1042.0 & $3.66 e-07$ \\
\hline
\end{tabular}

an example. The natural frequency decreases from $249.15 \mathrm{~Hz}$ down to $245.39 \mathrm{~Hz}$, decreased by $1.5 \%$, modal damping ratio increased from $6.05 e-04 \%$ to $4.77 e-03 \%$, increased by $87.3 \%$. Increasing the thickness of the viscoelastic damping block to improve the damping effect of the system is obvious.

4.4.2. Effect of Viscoelastic Damping Block's Storage Modulus. Change the storage modulus from $500 \mathrm{MPa}$ to $4000 \mathrm{MPa}$; the effect on natural frequency and modal damping ratio is shown in Table 8 and Figure 8.

As can be seen from Table 8 and Figure 8 , with the increase of the storage modulus of the viscoelastic damping block, the natural frequency of the VE-blade is decreasing, and the modal damping ratio is gradually increasing. Change the viscoelastic damping block's storage modulus from $500 \mathrm{MPa}$ to $700 \mathrm{MPa}$, the natural frequency decreased from $247.34 \mathrm{~Hz}$ down to $241.86 \mathrm{~Hz}$, decreased by $2.2 \%$, and modal damping ratio increased from $9.73 e-10 \%$ to $1.35 e-$ $9 \%$ increased by $27.9 \%$. It shows that selecting the damping material with large storage modulus is beneficial to improve the damping of the structure.

4.4.3. Effect of Viscoelastic Damping Block's Loss Factor. Change the loss factor from 0.5 to 1.5 ; the effect on natural frequency and modal damping ratio is shown in Table 9 and Figure 9.

As can be seen from Table 9 and Figure 9, with the increase of the loss factor of the viscoelastic damping block, the natural frequency of the VE-blade is decreasing, and the modal damping ratio is significantly increasing, especially in the third order. It is showed that the damping material with large loss factor is directly beneficial to improve the damping of the structure.

Change the viscoelastic damping block's loss factor from 0.5 to 0.7 , the natural frequency decreased from $247.34 \mathrm{~Hz}$ down to $241.87 \mathrm{~Hz}$, decreased by $2.2 \%$, and modal damping ratio increased from $1.01 e-3 \%$ to $1.39 e-3 \%$, increased by $27.3 \%$.

4.4.4. Effect of the Rotational Speed. Change the rotational speed from $0 \mathrm{rpm}$ to $60000 \mathrm{rpm}$, the dynamic frequency and modal damping ratio of the VE-blade are shown in Table 10 and the Campbell diagram of the viscoelastic damping blockblade is shown in Figure 10.

As can be seen from the Table 10, with the increase of rotational speed, the natural frequency of the VE-blade gradually increased, and the modal damping ratio decreased gradually. 


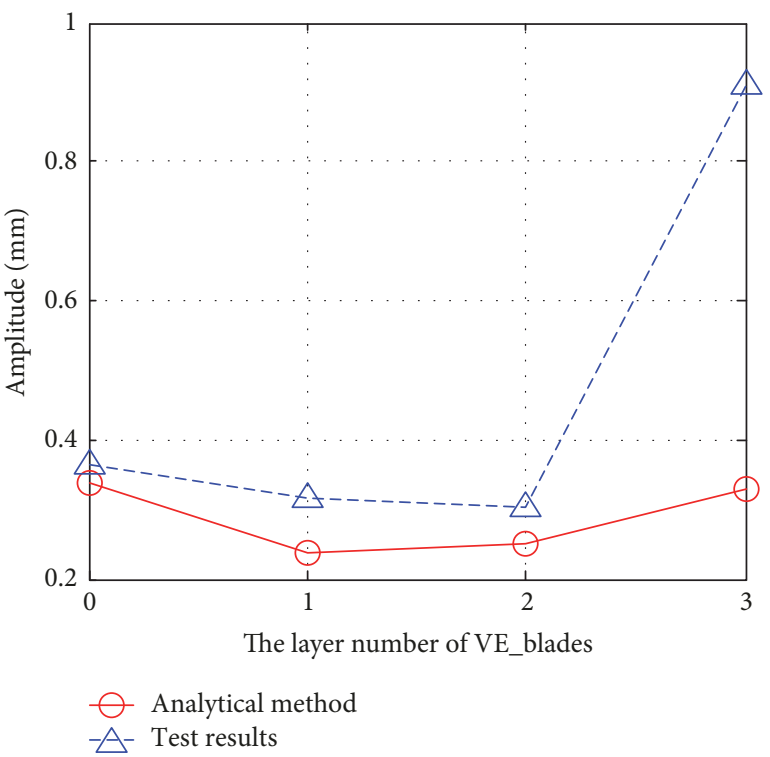

(a) The first order

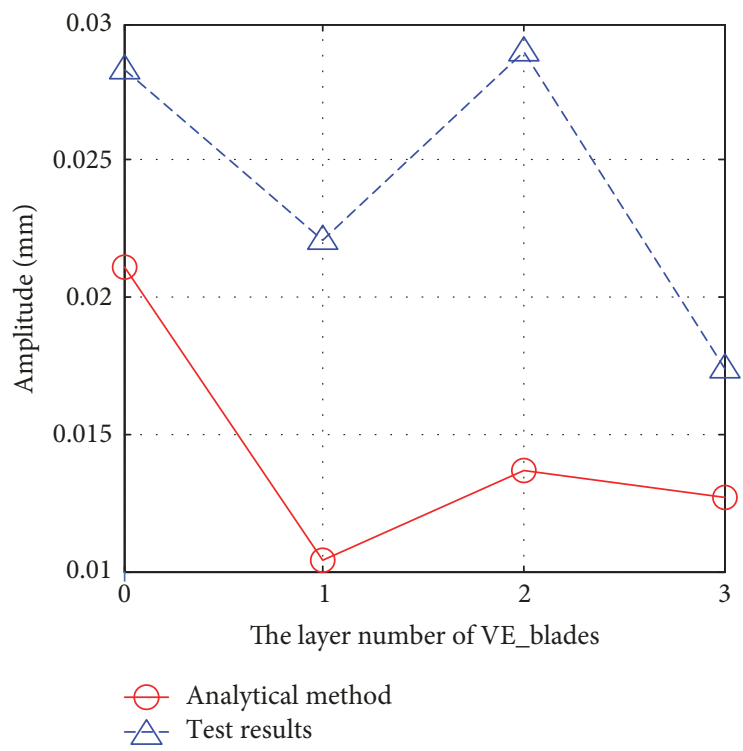

(b) The second order

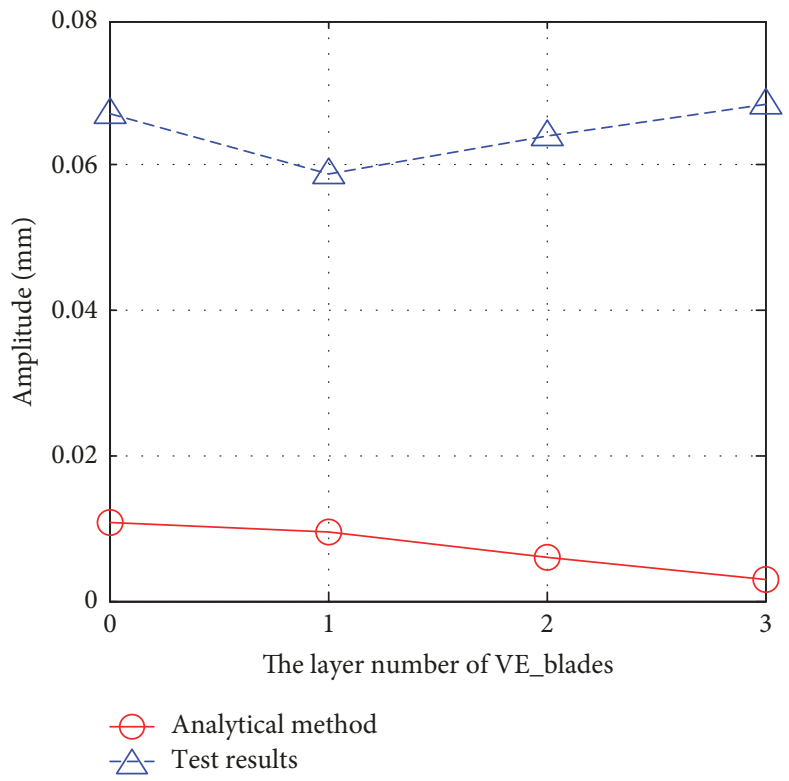

(c) The third order

FIGURE 6: Comparison of experimental results (solid line with circle) and simulation results (dotted line with triangle) of resonant response of VE-blade.

TABLE 9: Natural frequencies and modal damping ratios of the blade with different loss factors.

\begin{tabular}{lcccccc}
\hline \multirow{2}{*}{$\begin{array}{c}\text { Loss factor } \\
\text { Natural }\end{array}$} & $\begin{array}{c}\text { Modal damping } \\
\text { ratio/\% }\end{array}$ & $\begin{array}{c}\text { Second order } \\
\text { Natural } \\
\text { frequency/Hz }\end{array}$ & $\begin{array}{c}\text { Modal damping } \\
\text { ratio/\% }\end{array}$ & $\begin{array}{c}\text { Third order } \\
\text { Natural }\end{array}$ & $\begin{array}{c}\text { Modal damping } \\
\text { ratio/\% }\end{array}$ \\
\hline 0.5 & 247.34 & $1.01 e-3$ & 989.57 & $3.77 e-3$ & 1163.8 & $4.97 e-2$ \\
0.7 & 241.87 & $1.39 e-3$ & 967.66 & $5.21 e-3$ & 1138 & $6.88 e-2$ \\
0.9 & 236.57 & $1.77 e-3$ & 946.47 & $6.63 e-3$ & 1113.1 & 1089 \\
1.1 & 231.45 & $2.14 e-3$ & 925.97 & $8.02 e-3$ & 1065.6 & $1.06 e-1$ \\
1.3 & 226.49 & $2.50 e-3$ & 906.13 & $9.38 e-3$ & $1.24 e-1$ \\
1.5 & 221.68 & $2.86 e-3$ & 886.92 & $1.07 e-2$ & 1043 & $1.42 e-1$ \\
\hline
\end{tabular}



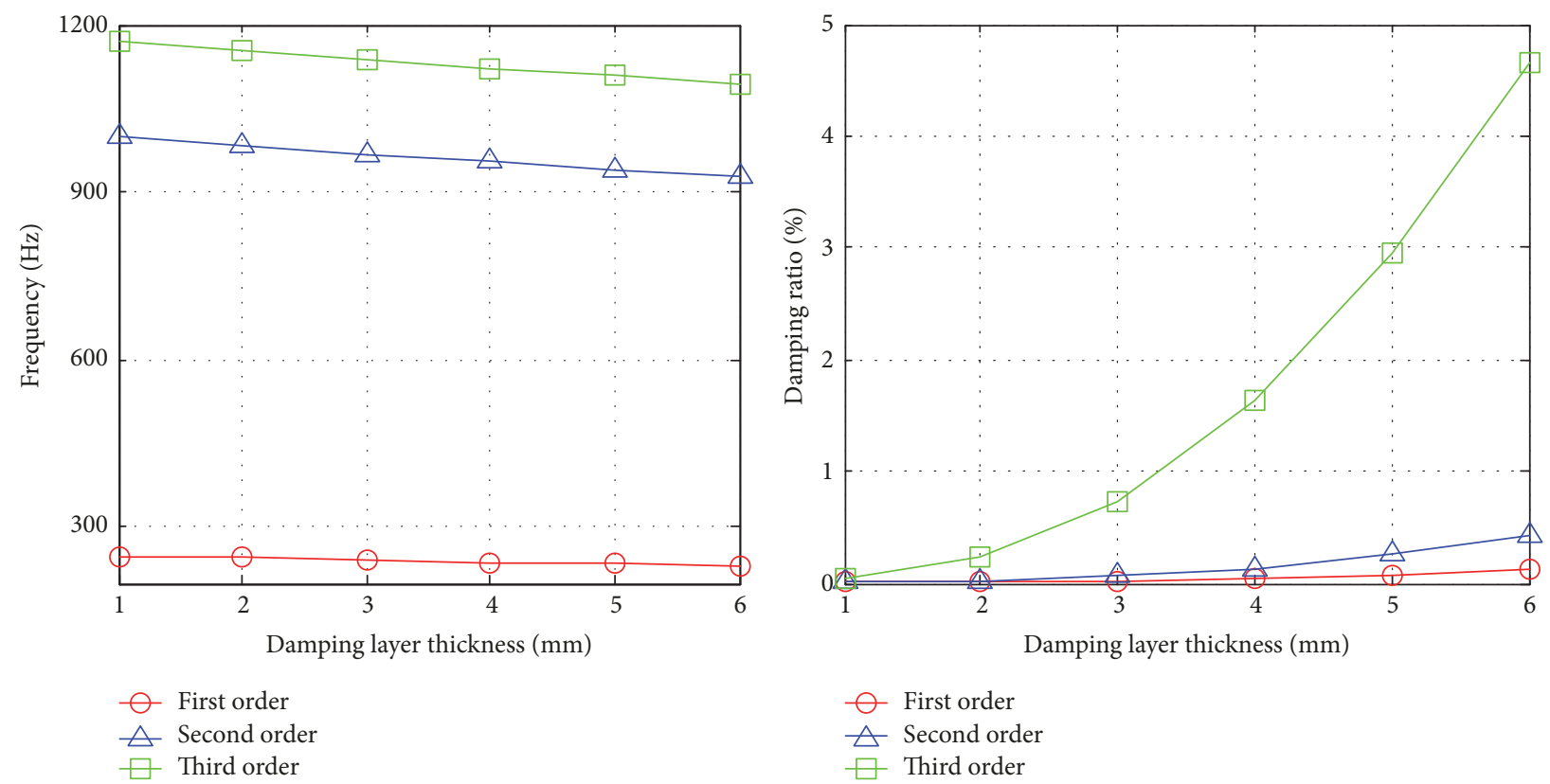

FIGURE 7: The thicknesses of viscoelastic damping block on the influence of natural frequencies and modal damping ratio of the blade.
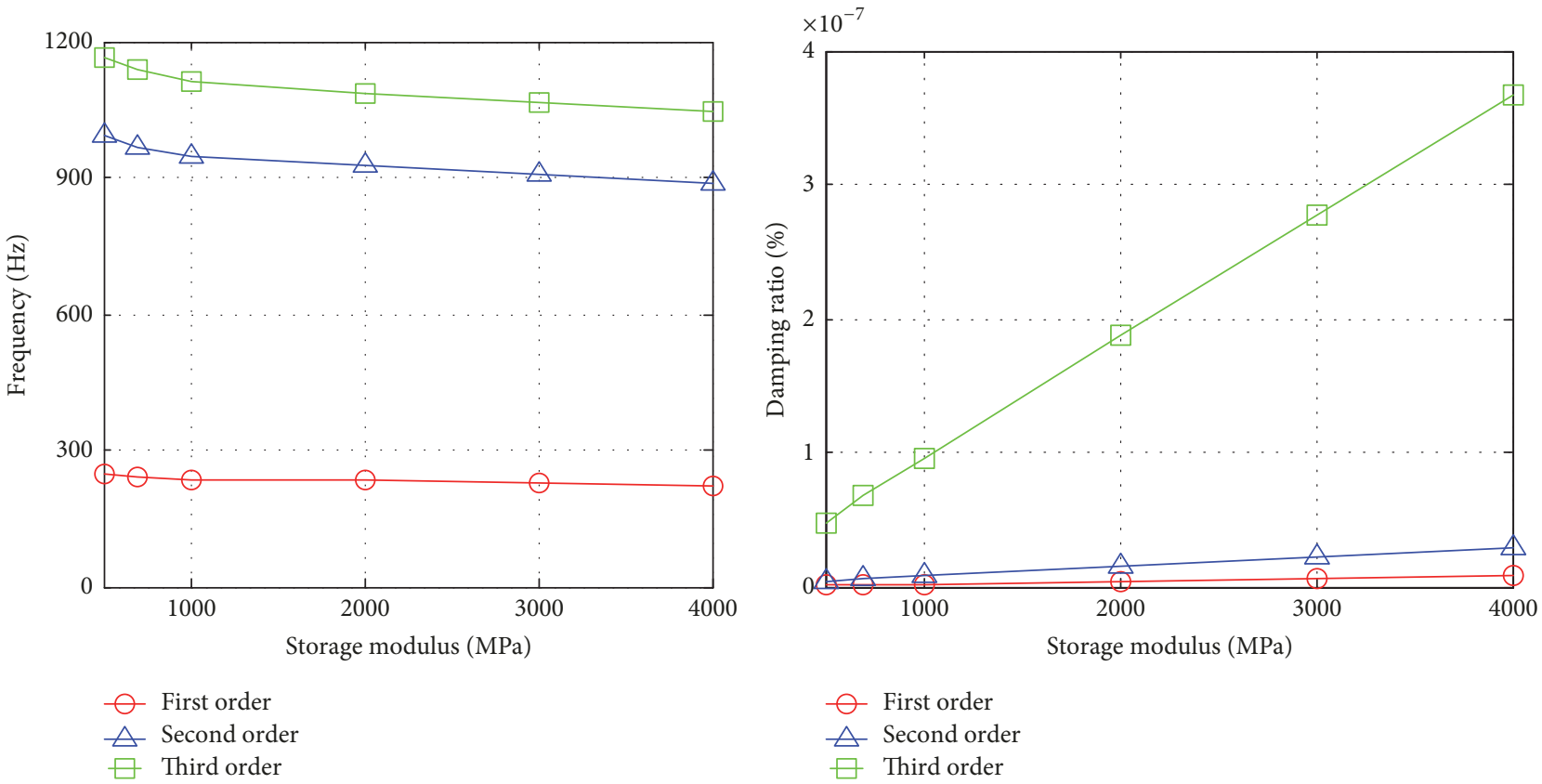

Figure 8: Natural frequencies and modal damping ratio of the blade under the influence of storage modulus.

Change the rotational speed from $10000 \mathrm{rmp}$ to $20000 \mathrm{rpm}$, the natural frequency increased from $247.34 \mathrm{~Hz}$ to $377.15 \mathrm{~Hz}$ and increased by $34.4 \%$; modal damping ratio decreased from $2.56 e-2 \%$ to $1.06 e-2 \%$, and decreased by $58.6 \%$. It shows that the damping effect of the viscoelastic damping block decreased with the increase of the rotational speed.

From Figure 10, when the VE-blade is working at about $10000 \mathrm{rmp}$, the second-order frequency curve and excitation vibration frequency line $k=7$ intersect, prone to resonance; when the VE-blade working speed range in 10000 $20000 \mathrm{rmp}$, the first-order frequency curve and excitation vibration frequency line $k=2$ intersect, prone to resonance; when the VE-blade working speed range in 40000 $50000 \mathrm{rmp}$, the third-order frequency curve and excitation vibration frequency line $k=7$ intersect, but its not within the working speed range; therefore it will not cause resonance. 

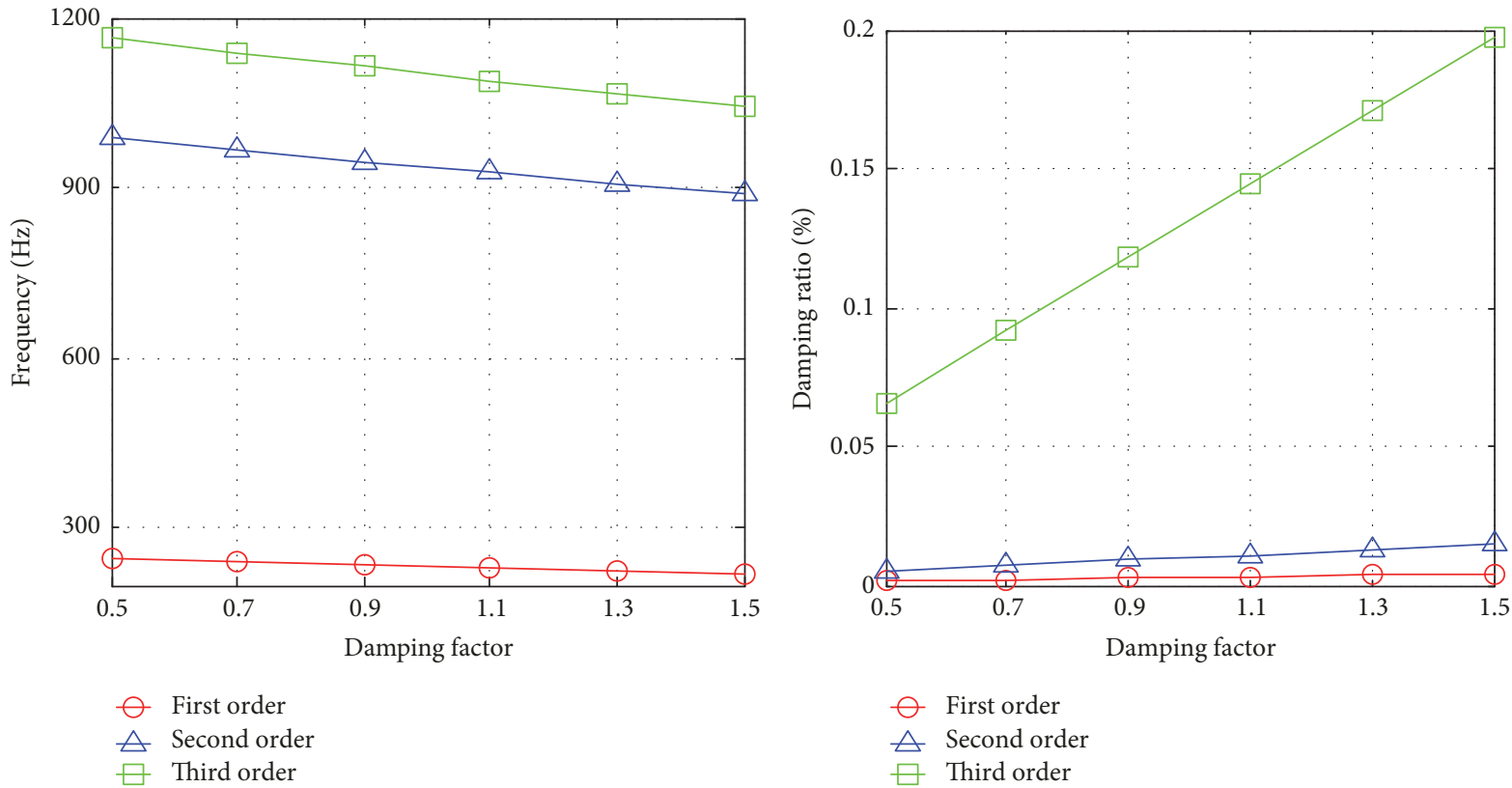

FIGURE 9: Natural frequencies and modal damping ratio of the blade under the influence of loss factor.

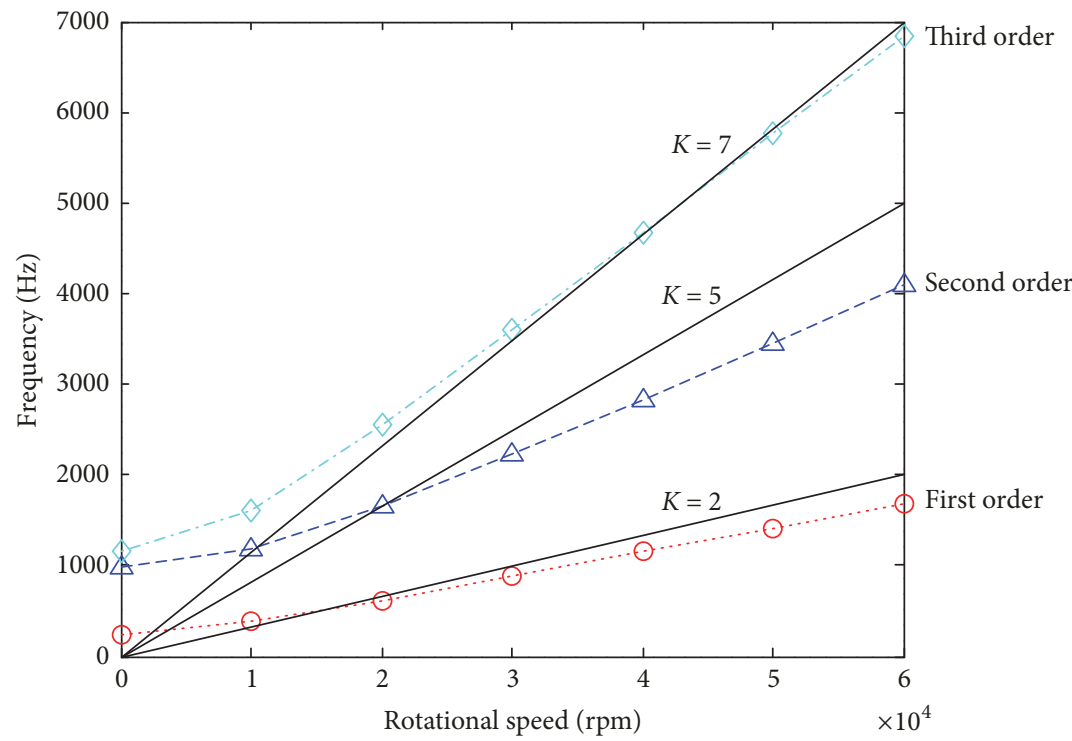

FIGURE 10: Campbell diagram of the blade with viscoelastic damping block.

TABLE 10: Dynamic frequencies and modal damping ratios of the blade with different rotating speeds.

\begin{tabular}{|c|c|c|c|c|c|c|}
\hline \multirow{2}{*}{$\begin{array}{l}\text { Rotational } \\
\text { speed/rpm }\end{array}$} & \multicolumn{2}{|c|}{ First order } & \multicolumn{2}{|c|}{ Second order } & \multicolumn{2}{|c|}{ Third order } \\
\hline & $\begin{array}{c}\text { Natural } \\
\text { frequency/Hz }\end{array}$ & $\begin{array}{c}\text { Modal damping } \\
\text { ratio/\% }\end{array}$ & $\begin{array}{c}\text { Natural } \\
\text { frequency/Hz }\end{array}$ & $\begin{array}{c}\text { Modal damping } \\
\text { ratio } / \%\end{array}$ & $\begin{array}{c}\text { Natural } \\
\text { frequency } / \mathrm{Hz}\end{array}$ & $\begin{array}{c}\text { Modal damping } \\
\text { ratio/\% }\end{array}$ \\
\hline 0 & 247.34 & $2.56 e-2$ & 989.5 & $9.58 e-2$ & 1162.8 & 1.26 \\
\hline 10000 & 377.15 & $1.06 e-2$ & 1182.5 & $6.42 e-2$ & 1614.2 & $6.28 e-2$ \\
\hline 20000 & 619.86 & $4.01 e-3$ & 1652.1 & $3.16 e-2$ & 2542.2 & $2.41 e-1$ \\
\hline 30000 & 882.34 & $2.09 e-3$ & 2224.8 & $1.68 e-2$ & 3587.6 & $1.16 e-1$ \\
\hline 40000 & 1149.3 & $1.30 e-3$ & 2835.5 & $9.97 e-3$ & 4666.7 & $6.57 e-2$ \\
\hline 50000 & 1417.3 & $8.82 e-4$ & 3462.0 & $6.45 e-3$ & 5756.4 & $4.13 e-2$ \\
\hline 60000 & 1685.3 & $6.31 e-4$ & 4095.1 & $4.44 e-3$ & 6848.2 & $2.80 e-2$ \\
\hline
\end{tabular}




\section{Conclusions}

Based on analytical analysis, numerical calculation, and test, the dynamic characteristic of the VE-blade is studied. The effects of various parameters including thickness, storage modulus, loss factor of viscoelastic damping block, and rotational speed on natural frequency and modal damping ratio of VE-blade are discussed in detail. Conclusions are as follows.

The VE-blade is simplified as a cantilever beam. Based on Euler Bernoulli beam theory, under the assumption of microvibration, moment of inertia and the nonlinearity of the strain and displacement are neglected. Compared with the experimental data, the rationality of the cantilever beam model and the mechanical simplification method is verified.

The first three-order natural frequencies of the blade decrease after applied a layer viscoelastic damping block. The first three-order natural frequencies decreased by $2.25 \%$, $2.23 \%, 2.14 \%$, respectively. Test results were reduced by $0.49 \%, 0.52 \%$, and $0.15 \%$, respectively. The experimental and simulation results show a trend consistency.

With the increase of viscoelastic damping block thickness, the influence on different orders resonant response is different. The resonant response decreased by $33.3 \%$, $26.2 \%$, and $3 \%$ in simulation result. In experiment result, it decreased by $13.36 \%$ and $16.87 \%$ and increased after applying three layers' viscoelastic damping block. The experiment and simulation result have the same trend after applying one and two layers viscoelastic damping block, which verified the rationality of the simulation result.

With the increase of the thickness of viscoelastic damping block, the storage modulus, loss factor, the natural frequency of VE-blade decreases and modal damping ratio increases. It is suggested that the appropriate increase of the thickness of the viscoelastic damping block, the selection of the material with larger energy storage modulus, and loss factor can improve the modal damping ratio of the system and obtain a better effect of vibration reduction.

With the increase of the rotational speed, the natural frequency of the VE-blade increases gradually, and the modal damping ratio decreases obviously, which shows that the damping effect of the viscoelastic damping block decreases with the increase of the rotational speed.

\section{Conflicts of Interest}

The authors declare that they have no conflicts of interest.

\section{Acknowledgments}

This work is financially supported by National Natural Science Foundation of China (no. 11502227) and Shandong Provincial Natural Science Foundation, China (no. ZR2014EEP006).

\section{References}

[1] X. Q. Zhou, D. Y. Yu, X. Y. Shao, S. Q. Zhang, and S. Wang, "Research and applications of viscoelastic vibration damping materials: A review," Composite Structures, vol. 136, pp. 460480, 2016.

[2] P. C. O. Martins, T. A. M. Guimarães, D. D. A. Pereira, F. D. Marques, and D. A. Rade, "Numerical and experimental investigation of aeroviscoelastic systems," Mechanical Systems and Signal Processing, vol. 85, pp. 680-697, 2017.

[3] G. J. Chang, Viscoelastic damping materials, National Defense Industry Press, Beijing, China, 2012.

[4] E. Balmes, M. Corus, S. Baumhauer, P. Jean, and J. Lombard, "Constrained viscoelastic damping, test/analysis correlation on an aircraft engine," in Structural Dynamics, Volume 3, Conference Proceedings of the Society for Experimental Mechanics Series, pp. 1177-1185, Springer New York, New York, NY, 2011.

[5] C. A. Bavastri, E. M. D. S. Ferreira, J. J. De Espíndola, and E. M. D. O. Lopes, "Modeling of dynamic rotors with flexible bearings due to the use of viscoelastic materials," Journal of the Brazilian Society of Mechanical Sciences and Engineering, vol. 30, no. 1, pp. 22-29, 2008.

[6] S. Ghinet and N. Atalla, "Modeling thick composite laminate and sandwich structures with linear viscoelastic damping," Computers \& Structures, vol. 89, no. 15-16, pp. 1547-1561, 2011.

[7] S. W. Park, "Analytical modeling of viscoelastic dampers for structural and vibration control," International Journal of Solids and Structures, vol. 38, no. 44-45, pp. 8065-8092, 2001.

[8] J. B. Deng, Z. G Zhu, and Q. H. Li, "Damping Characteristics of metal rubber damper on root of cantilever beam," Journal of Aerospace Power, vol. 13, no. 4, pp. 425-427, 1998.

[9] H. X. Li, Z. J. Huang, and L. Zhang, "New technique for elimination fault of the tenon of fan blade with mid-span shroud," Aeroengine, vol. no.2, pp. 27-31, 2002.

[10] R. T. Miao, "An analysis on break failure at dovetail of the 4th stage compressor blades of an engine," Gas Turbine Experiment and Research, vol. 16, no. 2, pp. 34-37, 2003.

[11] T. Kocatürk, "Determination of the steady-state response of viscoelastically supported cantilever beam under sinusoidal base excitation," Journal of Sound and Vibration, vol. 281, no. 3-5, pp. 1145-1156, 2005.

[12] Y. Wang and D. J. Inman, "Finite element analysis and experimental study on dynamic properties of a composite beam with viscoelastic damping," Journal of Sound and Vibration, vol. 332, no. 23, pp. 6177-6191, 2013.

[13] M. Rafiee, F. Nitzsche, and M. Labrosse, "Dynamics, vibration and control of rotating composite beams and blades: A critical review," Thin-Walled Structures, vol. 119, pp. 795-819, 2017.

[14] S. Kumar and R. Kumar, "Theoretical and experimental vibration analysis of rotating beams with combined ACLD and Stressed Layer Damping treatment," Applied Acoustics, vol. 74, no. 5, pp. 675-693, 2013.

[15] D. Biswas and M. C. Ray, "Active constrained layer damping of geometrically nonlinear vibration of rotating composite beams using 1-3 piezoelectric composite," International Journal of Mechanics and Materials in Design, vol. 9, no. 1, pp. 83-104, 2013.

[16] J. Austruy, F. Gandhi, and N. Lieven, "Rotor vibration reduction using an embedded spanwise absorber," Journal of the American Helicopter Society, vol. 57, no. 2, Article ID 022008, 2012.

[17] S. M. Hosseini, H. Kalhori, A. Shooshtari, and S. N. Mahmoodi, "Analytical solution for nonlinear forced response of a viscoelastic piezoelectric cantilever beam resting on a nonlinear elastic foundation to an external harmonic excitation," Composites Part B: Engineering, vol. 67, pp. 464-471, 2014. 
[18] J. B. Min, K. P. Duffy, B. B. Choi, A. J. Provenza, and N. Kray, "Numerical modeling methodology and experimental study for piezoelectric vibration damping control of rotating composite fan blades," Computers \& Structures, vol. 128, pp. 230-242, 2013.

[19] M. Kumar, R. A. Shenoi, and S. J. Cox, "Experimental validation of modal strain energies based damage identification method for a composite sandwich beam," Composites Science and Technology, vol. 69, no. 10, pp. 1635-1643, 2009.

[20] V. S. Rao, B. V. Sankar, and C. T. Sun, "Constrained Layer Damping of Initially Stressed Composite Beams Using Finite Elements," Journal of Composite Materials, vol. 26, no. 12, pp. 1752-1766, 1992.

[21] R. Rikards, A. Chate, and E. Barkanov, "Finite element analysis of damping the vibrations of laminated composites," Computers \& Structures, vol. 47, no. 6, pp. 1005-1015, 1993.

[22] S. S. A. Ravi, T. K. Kundra, and B. C. Nakra, "Response re-analysis of damped beams using eigenparameter perturbation," Journal of Sound and Vibration, vol. 179, no. 3, pp. 399-412, 1995.

[23] Y. M. Chen and H. R. Shi, "Vibration analysis of beams with partial constrained layer damping treatment," Machinery Design and Manufacture, vol. 5, pp. 103-105, 2009.

[24] M. Wang, H. R. Chen, R. X. Bai, and Y. H. Cai, "Dynamic characteriaics of composite reinforced laminates attached with frequency-dependent damping layers," Engineering mechanics, vol. 24, no. 10, pp. 64-70, 2007.

[25] S. H. Zhang and H. L. Chen, "A study on the damping characteristics of laminated composites with integral viscoelastic layers," Composite Structures, vol. 74, no. 1, pp. 63-69, 2006.

[26] F. Cortés and M. J. Elejabarrieta, "An approximate numerical method for the complex eigenproblem in systems characterised by a structural damping matrix," Journal of Sound and Vibration, vol. 296, no. 1-2, pp. 166-182, 2006.

[27] D. H. Liu, Application of viscoelastic damping vibration and noise reduction, Aerospace Publishing House, Beijing, China, 1990.

[28] A. D. Nashif, D. I. G Jones, and J. P. Henderson, Vibration Damping, John Wiley \& Sons, Inc, New York, NY, USA, 1985.

[29] Y. Cui, Dynamic research of rigid-flexibly coupling system in stream turbine blades, Harbin Engineering University, Harbin, China, 2008.

[30] M. O. Kaya, "Free vibration analysis of a rotating Timoshenko beam by differential transform method," Aircraft Engineering and Aerospace Technology, vol. 78, no. 3, pp. 194-203, 2006.

[31] D. J. Ewins, Modal testing: theory and practice, Research studies press, England, UK, 1984. 


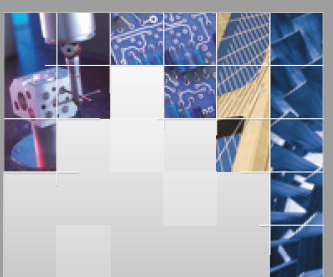

\section{Enfincering}
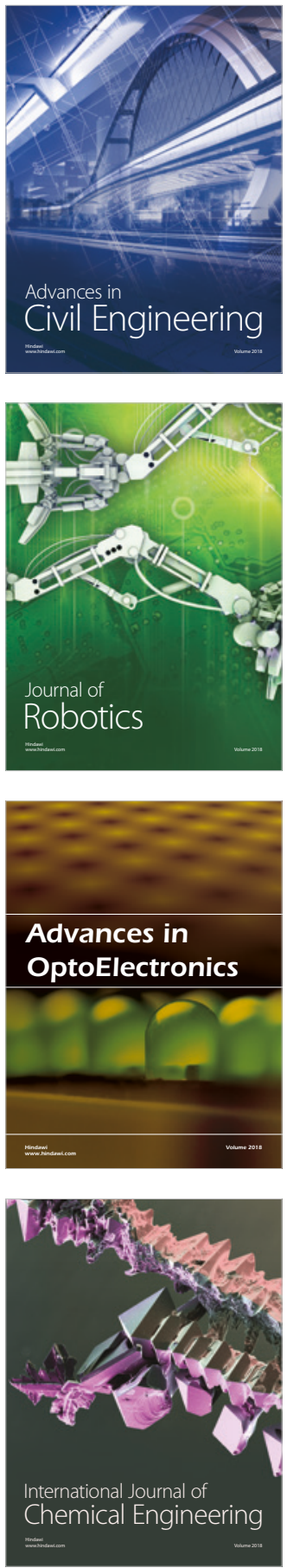

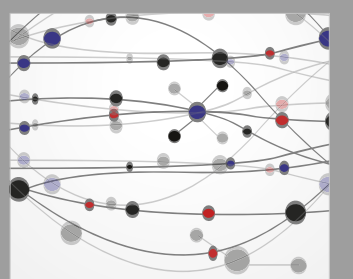

\section{Rotating \\ Machinery}

The Scientific World Journal

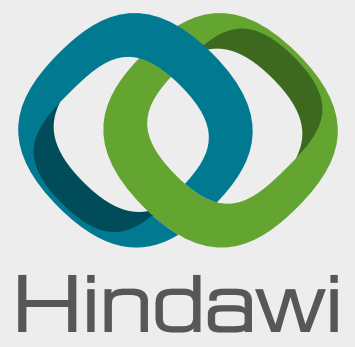

Submit your manuscripts at

www.hindawi.com
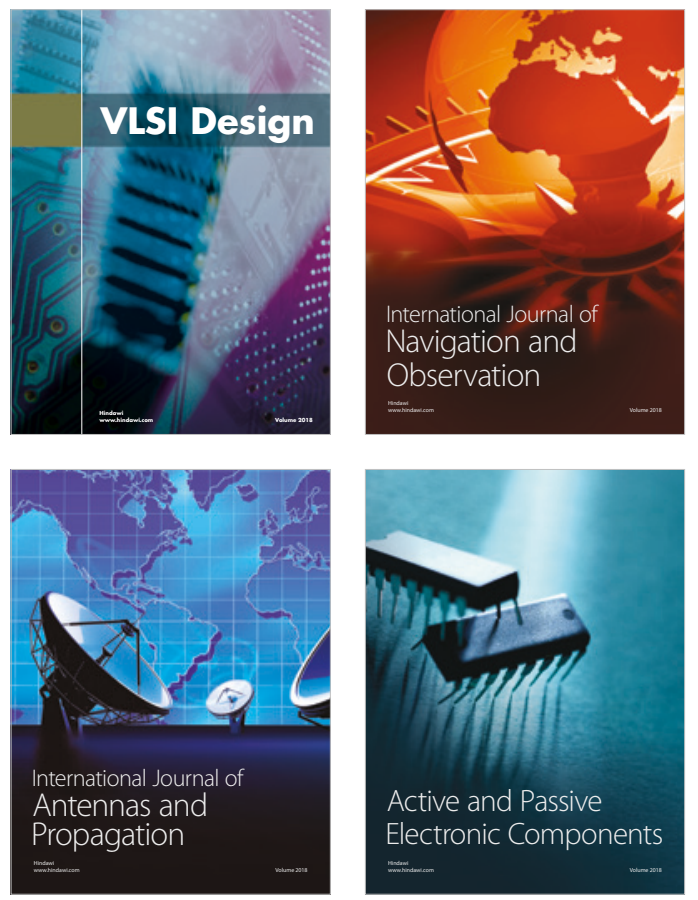
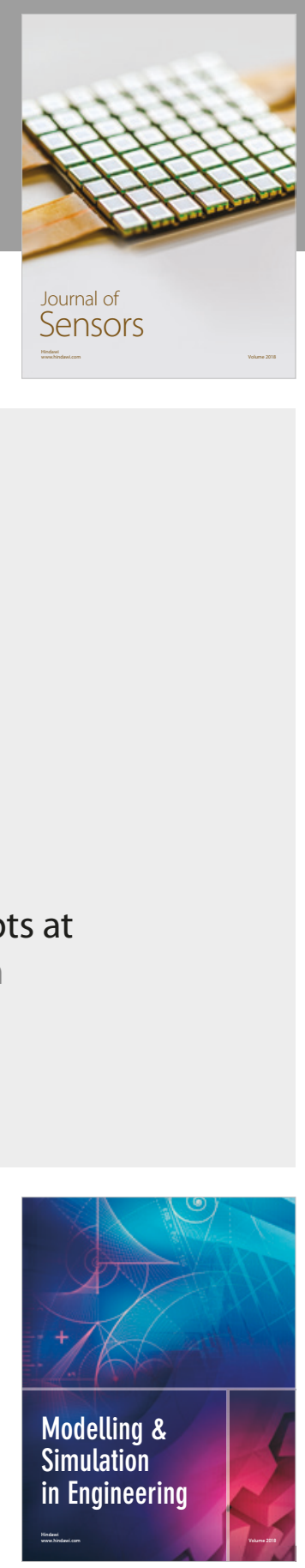

\section{Advances \\ Multimedia}
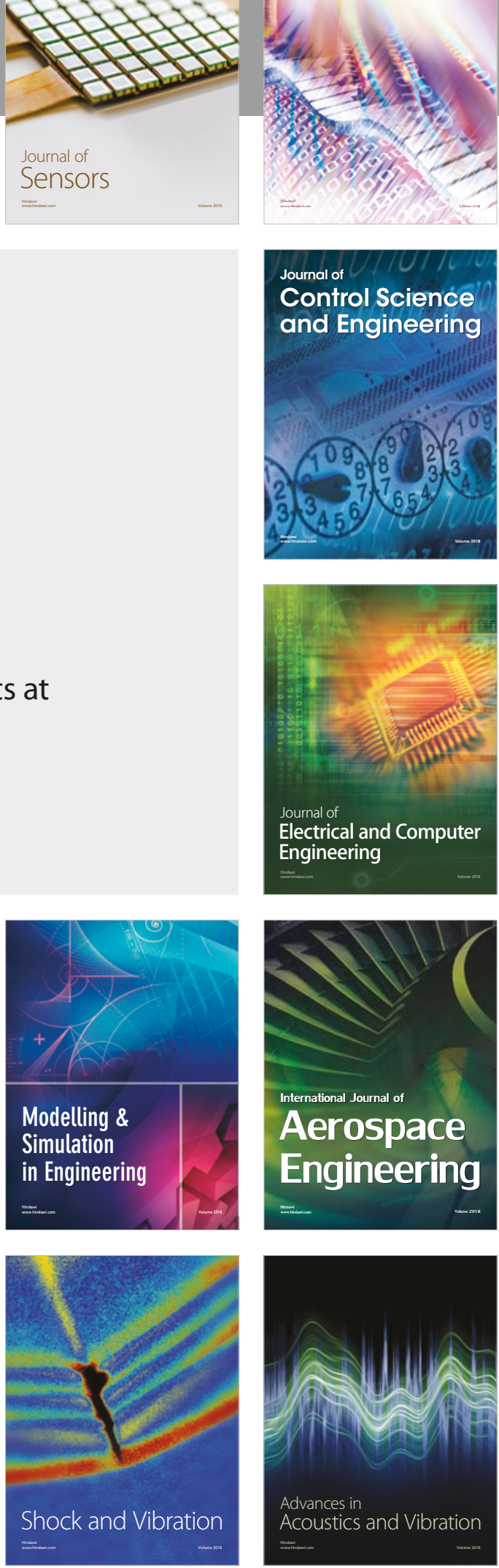